OPEN ACCESS

Edited by:

Silvia Turroni,

University of Bologna, Italy

Reviewed by:

Ravinder Nagpal,

Wake Forest School of Medicine

United States

Balamurugan Krishnaswamy,

Alagappa University, India

*Correspondence:

Cyril Poupet

cyril.poupet@gmail.com

tThese authors have contributed equally to this work

Specialty section:

This article was submitted to Nutrition and Microbes,

a section of the journal

Frontiers in Nutrition

Received: 18 February 2020

Accepted: 14 July 2020

Published: 21 August 2020

Citation:

Poupet C, Chassard C, Nivoliez A and Bornes S (2020) Caenorhabditis elegans, a Host to Investigate the Probiotic Properties of Beneficial Microorganisms. Front. Nutr. 7:135. doi: 10.3389/fnut.2020.00135

\section{Caenorhabditis elegans, a Host to Investigate the Probiotic Properties of Beneficial Microorganisms}

\author{
Cyril Poupet ${ }^{1 * t}$, Christophe Chassard ${ }^{1}$, Adrien Nivoliez ${ }^{2}$ and Stéphanie Bornes ${ }^{1+}$ \\ ${ }^{1}$ Université Clermont Auvergne, INRAE, VetAgro Sup, UMRF, Aurillac, France, ${ }^{2}$ Biose Industrie, Aurillac, France
}

Caenorhabditis elegans, a non-parasitic nematode emerges as a relevant and powerful candidate as an in vivo model for microorganisms-microorganisms and microorganismshost interactions studies. Experiments have demonstrated the probiotic potential of bacteria since they can provide to the worm a longer lifespan, an increased resistance to pathogens and to oxidative or heat stresses. Probiotics are used to prevent or treat microbiota dysbiosis and associated pathologies but the molecular mechanisms underlying their capacities are still unknown. Beyond safety and healthy aspects of probiotics, C. elegans represents a powerful way to design large-scale studies to explore transkingdom interactions and to solve questioning about the molecular aspect of these interactions. Future challenges and opportunities would be to validate $C$. elegans as an in vivo tool for high-throughput screening of microorganisms for their potential probiotic use on human health and to enlarge the panels of microorganisms studied as well as the human diseases investigated.

Keywords: Caenorhabditis elegans, probiotics, lifespan, pathogens, stress response, immunity

\section{INTRODUCTION}

With the advent of probiotic microorganisms, including lactic acid producing bacteria (LAB), in the treatment of diseases related to dysbiosis, there is the question of understanding the mechanisms of action of these strains. How to efficiently screen microorganisms' collections to select new probiotics for innovative therapeutics applications is an emerging question as well.

Probiotics have been officially defined in 2001 by both the Food and Agriculture Organization of the United Nations (FAO) and the World Health Organization (WHO) as "live microorganisms which, when administered in adequate amounts, confer a health benefit on the host" (1). A new name is increasingly used to replace the term probiotic: live biotherapeutic products (LBP). These LBP are biological products containing live biotherapeutic microorganisms (LBM) used to prevent, treat, or cure a disease or condition of human beings, excluding vaccines (2). Under this appellation, a wide variety of microbial species is found within both prokaryotes and eukaryotes (yeasts) although there are mainly lactic bacteria such as Lactobacillus strains.

In general, the mechanisms of action of probiotic species are poorly characterized and often based on empirical data as survival studies in the gut or immunomodulation $(3,4)$. At present, selection of new probiotic strains is based on a series of tests both in vitro and in vivo. The main in vitro tests commonly used are: the tolerance to acidity and gastric enzymes, the tolerance to bile, and intestinal enzymes, the adhesion to intestinal cells and the persistence in the digestive tract, and the lack of pathogenic behavior (5). In vitro tests are informative but complementary in vivo 
approaches is mandatory for a better characterization of probiotics mechanism of action but also safety aspects.

The selection of new microbial strains with probiotic potential as well as the characterization of their properties have been based on experiments using in vitro models (cell cultures). These have an undeniable advantage: strict control of the experimental conditions (e.g., nature of the culture media, quantity of microorganisms, temperature, $\mathrm{pH}$, etc.) as well as interactions between a limited number of microorganisms, most often using binary models. This facilitates the analysis and interpretation of the observed effects. However, the experimental conditions are particularly distant from the complex conditions found in a host. In addition, research into probiotic microorganisms is facing new challenges with increasing regulatory pressure from the European Union and the United States of America. These regulatory obstacles impose on pharmaceutical laboratories manufacturing probiotics and therefore on research teams, the use of relevant methods and models to study probiotic strains, by combining in vitro and in vivo approaches. It is only with this finer characterization that the laboratories will be able to justify more firmly the interest of using their products for health applications (6). However, in the same way as for in vitro models, depending on the scientific (historical) context and the objective to be achieved, it will be advisable to select the most pertinent model before the final essential study which is to carry out clinical trials in humans (7). Regarding to in vivo tests, many studies involve laboratory animals (e.g., rats, mice, rabbits, or guinea pigs) or clinical trials on the human population for the last stages of research. These clinical trials, although very important to determine the effectiveness of the strain and the potential harmful effects, are particularly expensive, time-consuming and difficult to implement (8). There is a need for in vivo alternatives, easier to handle but sufficiently close to humans for the in vivo and large-scale probiotic studies. In any case, the thorough study of gut microbiota remains difficult and requires a lot of steps combining in vitro studies, tests on laboratory animals and finally on humans (9).

The current number of in vivo methods for fast and reliable analysis of collections using complex multicellular models is too limited. Mainly for cost reasons, infrastructure and ethics, it is definitely not possible anymore to use quantities of laboratory animals such as mice or rats during the early stages of research $(10,11)$. For over 30 years, at least 4,000 researchers around the world have turned to Caenorhabditis elegans in fields such as ecotoxicology, neurobiology, degenerative disease, aging, hostmicroorganism interactions, and recently virus-host interactions (12-14). C. elegans, which was described for the first time in 1900 by Maupass (15), was introduced into laboratories in the late 1960s by Sidney Brenner who made it a model in genetics. His work, which won him the Nobel Prize in Medicine in 2002, allowed a detailed understanding of the molecular mechanisms of the regulation of gene expression, cell polarity, apoptosis, organogenesis, and aging $(16,17)$. C. elegans is a $1 \mathrm{~mm}$ long worm, living in the soil and usually feeding on bacteria. It is a self-fertilizing hermaphrodite nematode with many laboratory advantages. Among these advantages are the simple growth conditions, a short generation time (18), a transparent body facilitating fluorescence microscopy observation, the ability for genetic engineering and a low cost of use. Thanks to its sensory neurons allowing it to detect different chemical signatures, it is able to select its food and at the same time avoid pathogenic microorganisms (19). The generation of one million mutants obtained in a few weeks will be contained in 20 Petri dishes at a cost equivalent to that of a single mouse (20). Considering the morphological aspect of the animal, its intestine is a major organ with one third of the total somatic mass (21). The morphology of intestinal cells as well as the phenomena of endocytosis and exocytosis display similarities with humans (22). The $97 \mathrm{Mbp}$ worm's genome is fully sequenced (23) and contains 19,099 genes, almost as much as the human genome. Seventy-four percent of human proteins have homologs in the model organism $C$. elegans (24). This sequence and annotation knowledge allowed the generation by the Caenorhabditis Genetic Center (CGC) of more than 12,000 different strains (wild, mutants), all genetically characterized, facilitating the mechanistic research using the nematode. Key genes regulating in a global way the metabolism and the life expectancy of $C$. elegans such as the daf-2 and daf-16 genes, respectively encoding for an insulin receptor and for a Forkhead box O (FOXO) transcription factor, were identified. They are involved in the expression of genes encoding chaperone, antioxidant, or antimicrobial proteins via the Insulin/IGF-1 mediated signaling pathway (IIS), all leading to the modulation of the worm's health condition and consequently of its lifetime (25-27).

Several antimicrobial pathways found in mammals are also found in the worms suggesting it is a powerful model to explore immunological mechanisms $(28,29)$. Finally, since the first infection model involving Pseudomonas aeruginosa in $1999(30,31)$, a lot of studies reported the susceptibility of the worm to numerous bacterial and fungal pathogens, some of them infecting humans such as Pseudomonas aeruginosa (32), Enterococcus faecalis (33), Staphylococcus aureus, Salmonella, Escherichia coli O157:H7, or Klebsiella pneumoniae (34-37). Considering all these points, C. elegans could be a relevant go-between host model between in vitro and mammalian models for the investigation of host-microorganism interactions at the molecular level using direct genetic and mechanistic approaches.

This review is focused on studies using C. elegans to investigate its interaction with lactic acid bacteria having evidenced probiotic capacities. The pertinence and the advantages of using $C$. elegans as a model organism to identify new potentially probiotic strains are analyzed. The new way to use the worm, with the aim to screen microorganisms' collections for specific probiotic characters, is also detailed in the manuscript. This manuscript was written from an exhaustive review of the scientific literature related to the $C$. elegans model and the in vivo characterization of microbial strain with probiotic potential. All recent articles have been considered without distinction and studied objectively to avoid bias. The compilation of bibliographic data, from the PubMed database, was carried out in three stages. The first, relating to the comparison of experimental models, was done using the keywords experimental models, in vivo, comparison, mice, 
rat, zebrafish, C. elegans, Drosophila melanogaster, and Galleria mellonella. The second, in connection with the use of the C. elegans model as the study of probiotics, required the following key words C. elegans, probiotic, live biotherapeutic microorganism, mechanisms, immunity, and pathway. Finally, for the third step, the keywords C. elegans, high-throughput, translational, and prospects were used. In all three steps, the logical operator "AND” was used.

Fifty-two publications focused on C. elegans and probiotics are referenced in PubMed database, 19 out of 48 have been published from 2018, 11 of whom in 2019 and already 11 in 2020, confirming the emergence of this model in this research domain.

\section{C. elegans MODEL ADVANTAGES AND LIMITATIONS COMPARED TO OTHER IN VIVO MODELS}

The use of in vivo techniques to explore the world of probiotics has made it possible to describe a large variety of models with very varied complexities. These can be as simple as multicellular organisms like worms, flies (invertebrates) as well as being particularly sophisticated like knockout mice or humans (clinical trials). All these models provide the scientific community with a very large amount of information, but they also have certain drawbacks. Consequently, it is essential to choose with discernment and rigor the model which will be the most adapted to the scientific question based on technical, ethical, economic aspects, and according to scientific context. Therefore, while the characterization and evaluation of the properties of a probiotic strain should be carried out directly within the target population, a preselection of the strains is essential before testing it using appropriate in vivo models $(6,38)$. Two kinds of models are commonly used, the vertebrate and the invertebrate organisms. The Table 1 lists the advantages and the limitations of the most commonly used models in the context of probiotics characterization but among the limits of their use are ethics and legislation.

\section{Vertebrate Models}

The scientific community now has vertebrate animal models allowing investigations in most fields of biology. The best known are the rat (Rattus norvegicus), the mouse (Mus musculus), the zebrafish (Danio rerio), the pig (Sus domesticus), the guinea pig (Cavia porcellus), the macaque (Macaca mulatta), the cat (Felis sylvestris catus), or the dog (Canis lupus familiaris) to name a few. However, among this multitude and due to their similarities to humans, only a few models are commonly used in the laboratory, mainly due to regulatory and ethical constraints, the complexity of use, but also the particularly high cost they can represent. The pig (Sus domesticus) is notably used for the selection of probiotics, often directed against infections with Escherichia coli or Clostridioides difficile, but rarely for mechanistic purposes. The use of the dog or the monkey is quite marginal and is mainly restricted to very specific areas because their implementation requires considering considerable ethical considerations (6).

\section{The Mouse Mus Musculus}

The laboratory mouse M. musculus is a powerful model for the evaluation of host-microbiota interactions, in relation to human biology (40-42). About 99\% of mouse genes are shared with humans, and the two organisms share significant similarities in the microbiome (Firmicutes, Bacteroidetes, and Actinobacteria). Many genetic tools are available to the scientific community: many strains inbred or not, a collection of mutants and the possibility of carrying out RNA interference in vivo. However, experimental limitations exist. The skin, fur, and oropharyngeal structures, compartmentalization of the digestive tract and behavior are different from those of humans and can have a great influence on microbial communities and therefore their impact on the host (43). A significant proportion of microorganisms from human origin are unable to colonize the murine intestine and the taxa which colonize it do not induce certain responses usually observed in the presence of the native microbiota $(44,45)$.

\section{The Rat Rattus Norvegicus}

The rat is the second rodent species used in research as a model for preclinical study (46). Closer physiologically to humans, it allows to obtain experimental results that are more easily transposable to humans (47). Like for the human, the intestinal microbiota of the rat is dominated by three large phyla: Firmicutes, Bacteroidetes, and Proteobacteria (48). The animal is used to study the impact of bacteria with probiotic potential on the intestinal level, in the case of inflammatory syndromes, in particular in connection with obesity (49-52). However, the development of the rat model has until recently been slowed down by the lack of available mutants, the first of which were only generated by genome editing tools in 2010 (53). Since then, different methods of transgenesis have been successfully applied which should accelerate the development of mutants (54).

\section{The Zebrafish Danio Rerio}

The zebrafish $D$. rerio, with its varied microbiota, is becoming a powerful model for studying the complexity of hostmicrobiota interactions. It has several characteristics that make it an attractive experimental system. The external fertilization and transparency of embryos and larvae allow the visualization of developing cells as well as the colonization of microorganisms. Its rapid development, its small size, its high degree of homology with mammals make the zebrafish a tool interesting for mechanistic studies, not only in the adaptive immune system (TLR and NOD receptors), but also in the digestive system (43). Limitations of the zebrafish model in microbiota research include differences in environmental conditions compared to humans and other model organisms (55). Although the fecal microbiota of humans and rodents can vary, it is still dominated by the phyla Firmicutes and Bacteroidetes. The zebrafish gut microbiota is dominated by Proteobacteria and Fusobacteria, with variable presence of Firmicutes, Cyanobacteria, and Actinobacteria, and it varies considerably from one laboratory to another, notably depending on the diet $(56,57)$. 
TABLE 1 | Comparison of vertebrate and invertebrate models used for microorganism-host, microorganism-microorganism and microorganism-microorganism-host interactions.

\begin{tabular}{|c|c|c|c|c|c|c|}
\hline & \multicolumn{3}{|c|}{ Vertebrates models } & \multicolumn{3}{|c|}{ Invertebrates models } \\
\hline & Mus musculus & Rattus norvegicus & Danio rerio & $\begin{array}{l}\text { Drosophila } \\
\text { melanogaster }\end{array}$ & Galleria mellonella & $\begin{array}{l}\text { Caenorhabditis } \\
\text { elegans }\end{array}$ \\
\hline $\begin{array}{l}\text { Full genome } \\
\text { sequence available }\end{array}$ & Yes & Yes & Yes & Yes & Yes & Yes \\
\hline $\begin{array}{l}\text { Resources needed } \\
\text { in the laboratory }\end{array}$ & Very high & Very high & High & Low & Low & Low to high \\
\hline $\begin{array}{l}\text { Ease of } \\
\text { implementation }\end{array}$ & High & High & Low & Low & Low & Low \\
\hline $\begin{array}{l}\text { Mutants available in } \\
\text { public bank }\end{array}$ & Yes & No & Yes & Yes & No & Yes \\
\hline RNAi bank available & No & No & No & Yes & No & Yes \\
\hline Major intestinal taxa & $\begin{array}{l}\text { Firmicutes, } \\
\text { Bacteroidetes, } \\
\text { Actinobacteria }\end{array}$ & $\begin{array}{l}\text { Firmicutes, } \\
\text { Bacteroidetes, } \\
\text { Proteobacteria }\end{array}$ & $\begin{array}{l}\text { Proteobacteria, } \\
\text { Fusobacteria }\end{array}$ & $\begin{array}{l}\text { Lactobacillus, } \\
\text { Acetobacter }\end{array}$ & $\begin{array}{l}\text { No microbiota in } \\
\text { laboraroty condition }\end{array}$ & $\begin{array}{l}\text { No microbiota in } \\
\text { laboratory condition }\end{array}$ \\
\hline $\begin{array}{l}\text { Survival at } 37^{\circ} \mathrm{C} \\
\text { (human body } \\
\text { temperature) }\end{array}$ & Yes & Yes & No & No & Yes & No \\
\hline Immunity & $\begin{array}{l}\text { Innate and } \\
\text { adaptative }\end{array}$ & $\begin{array}{l}\text { Innate and } \\
\text { adaptative }\end{array}$ & $\begin{array}{l}\text { Innate and } \\
\text { adaptative }\end{array}$ & Innate & Innate & Innate \\
\hline Axenic animals & $\begin{array}{l}\text { Yes but technically } \\
\text { demanding and very } \\
\text { expensive }\end{array}$ & $\begin{array}{l}\text { Yes but technically } \\
\text { demanding and very } \\
\text { expensive }\end{array}$ & $\begin{array}{l}\text { Yes but limited in } \\
\text { time }\end{array}$ & Yes & Yes & Yes \\
\hline $\begin{array}{l}\text { Compatibility with } \\
\text { human origin } \\
\text { microorganisms }\end{array}$ & Variable & Variable & $\begin{array}{l}\text { Yes but limited to } \\
\text { aerobic taxa }\end{array}$ & $\begin{array}{l}\text { Yes but limited to } \\
\text { aerobic taxa }\end{array}$ & $\begin{array}{l}\text { Yes but limited to } \\
\text { aerobic taxa }\end{array}$ & Yes \\
\hline Screening platform & No & No & Yes & Yes & Yes & Yes \\
\hline $\begin{array}{l}\text { Usable for } \\
\text { high-throughput } \\
\text { studies }\end{array}$ & No & No & Yes & Variable & Yes & Yes \\
\hline $\begin{array}{l}\text { Microscopic } \\
\text { observation on live } \\
\text { whole animal }\end{array}$ & No & No & Yes & No & No & Yes \\
\hline Ethical issues & Yes & Yes & No & No & No & No \\
\hline Other limitations & $\begin{array}{l}\text { Impact of skin, fur, } \\
\text { digestive tract and } \\
\text { behavior on } \\
\text { microbial } \\
\text { communities }\end{array}$ & $\begin{array}{l}\text { Impact of skin, fur, } \\
\text { digestive tract and } \\
\text { behavior on } \\
\text { microbial } \\
\text { communities } \\
\text { Lack of mutants }\end{array}$ & $\begin{array}{l}\text { High variability of the } \\
\text { gut microbiota } \\
\text { based on } \\
\text { experimental and } \\
\text { environmental } \\
\text { conditions }\end{array}$ & $\begin{array}{l}\text { Low diversity of the } \\
\text { gut microbiota } \\
\text { High-throughput } \\
\text { methods difficult to } \\
\text { implement } \\
\text { Injecting a pathogen } \\
\text { bypasses the early } \\
\text { stages of infection }\end{array}$ & $\begin{array}{l}\text { No mutants } \\
\text { Low standardization } \\
\text { between laboratories }\end{array}$ & $\begin{array}{l}\text { Time consuming without } \\
\text { automation } \\
\text { Impact of temperature } \\
\text { on microbial metabolism }\end{array}$ \\
\hline
\end{tabular}

Adapted from Douglas (7) and Nathan (39).

\section{Ethics and Legislation}

Researchers who need animal models are faced with ethical and legal considerations. In addition, public opinion is often not aware of the economic and societal importance of the proposed research or of the regulatory context, which also limits the unethical use of animal suffering. Researchers must also actively ensure that animal models (i) are scientifically (and statistically) validated (ii) cannot be replaced by in vitro alternatives and (iii) minimize animal suffering by limiting the number of animals and the duration of the experiment to what is statistically required. Research strategies and methods must be constantly challenged and objectively examined against the $3 \mathrm{R}$ rule established more than 50 years ago, that is, using the possibilities of replacement, reduction, and refinement (58). In addition to the proper management of pain by analgesia and anesthesia, the welfare facilities have improved considerably in accordance with the latest American and European guidelines for the accommodation of animals. Mice and rats must have sufficient space, of sufficient complexity, to express a wide range of normal behaviors and to provide enrichment opportunities to promote physical exercise, foraging, eating, manipulation and cognitive activities $(6,59)$.

\section{Invertebrate Models}

Among the invertebrate laboratory models are the fly (Drosophila melanogaster), the greater wax moth (Galleria mellonella), and the roundworm (Caenorhabditis elegans). These models are commonly used in the laboratory, mainly due to the facilities 
in terms of legislation and ethics, their easy way of use, but also their low cost. The potential probiotic capacities of new strains need the use of different and complementary approaches to be elucidated. The invertebrates represent inbetween models complementary to in vitro approaches and allowing the identification of scientific hypothesis justifying the use of vertebrate models.

\section{The Fly Drosophila Melanogaster}

D. melanogaster can allow reliable validation of probiotic effects on a living organism: high throughput screening capabilities, inexpensive and rapid reproduction, and microbiome easy to handle. In addition, many tools for studying host-microbe interaction in D. melanogaster are already available due to its rich history in pathogen research (60). Compared to the gastrointestinal tract of mammals, the intestine of D. melanogaster has several major differences, but the gastrointestinal physiology, anatomy and signaling are highly conserved (61). A wide range of strains of D. melanogaster available from public banks can be derived germ-free and easily maintained without requiring expensive animal facilities, equipment, and technicians (62). Compared to the human microbiota, the D. melanogaster microbiota has a low microbial diversity ( 1 to 30 species) and is generally dominated by Lactobacillus and Acetobacter (63-65). These characteristics make D. melanogaster an ideal high-throughput in vivo model for understanding host-microbiota interactions (66), in particular for screening bacteria with probiotic potential (67). However, there are weaknesses limiting the use of the fly as a model. Indeed, the infection of the animal by a microbial strain is carried out by a direct injection, which bypasses the mechanisms put in place during the first stages of an infection.

\section{The Greater Wax Moth Galleria Mellonella}

While it is not (yet) as genetically modifiable as D. melanogaster or C. elegans, the simplicity of handling and infection of the larvae of $G$. mellonella combined with their survival at 25 and $37^{\circ} \mathrm{C}$ makes this animal a promising model (39). In research on bacterial $(68,69)$ and fungal $(70,71)$ pathogenesis, the larvae of G. mellonella have been shown to be a relevant model of infection. In their study, Vilela et al. used larvae as a model for pathogenic yeast infection $C$. albicans and co-infection with a beneficial strain of Lactobacillus acidophilus (72). Unlike D. melanogaster and $C$. elegans, fungal or bacterial infections and the immune defense mechanisms of the host in G. mellonella seem to be very close to those encountered in humans (39). Conversely, the lack of a complete genome sequence, the absence of mutant strains and the need for standardization between different sources and laboratories $(39,69)$, are currently curbing the enthusiasm for this model.

\section{The Roundworm C. elegans}

The strength of $C$. elegans as a model organism for microbiome research is its ability to conduct high- throughput experiments with a gnotobiotic organism and to explore the complex cause and effect relationship between presence and absence of a microbial species and a phenotype reflecting good or bad health. In fact, the microorganisms that pass through the pharynx to the intestine represent the only nutritive source for nematodes. They can thus influence the physiology of the animal through their metabolites (73). In addition, the use of nematodes for the screening of probiotics is favored by the possibility of easily monitoring anti-aging markers, as well as the storage of body fat $(74,75)$. In addition, several genes involved in the stress response and linked to immunity are highly conserved between humans and nematodes (76).

Today, the growing interest in the effects on longevity due to probiotics has led to the need for practical in vivo models to understand the mechanisms of probiotic activity. In recent years, the C. elegans nematode has become a powerful animal model for studying host-probiotic interactions. Its advantages include ease of handling, transparency of the body, short lifespan, and the absence of ethical issues. Another important tool of C. elegans is the availability of transgenic animals. Many mutants, available in libraries (CGC, https://cgc.umn.edu/), can help study the mechanism of action at the molecular level of a compound or pathways involved in the host-microorganism interaction. A collection of E. coli strains enabling RNAi feeding to be carried out in C. elegans is also available to the scientific community (C. elegans RNAi Collection, The Wellcome CRC Institute, University of Cambridge, UK, https://www.sourcebioscience. com/life-science-research/clones/rnai-resources/c-elegans-rnaicollection-ahringer/). For example, in an infectious context, the use of transgenic GFP nematodes makes it possible to study the response in vivo by fluorescence analysis $(77,78)$. Also, several online and freely accessible tools allow any type of researcher (beginner, confirmed, or expert) to access a large amount of data on the model, covering as well the fields of fundamental biology as applied (WormBase, https://wormbase. org/; WormWiring, https://www.wormwiring.org/; WormAtlas, https://www.wormatlas.org/; WormBook, http://wormbook. org/; OpenWorm, http://openworm.org/).

C. elegans model allows transcriptomic, proteomic and networks analysis, offering promising mechanistically insights opportunities (79-81). Moreover, C. elegans opens new perspectives in developing assays to investigate the cytotoxicity of new bioactive molecules or microbial pathogenicity and host defense mechanisms and gives new strategies to understand the mode of action (specific chemical, virulence factor). C. elegans allows the following of a microorganism in a whole animal with an integrated point of view, considering the gene expression using transcriptomic and proteomic approaches as well as metabolomics and physiology of the entire organism (82).

Because of its easy-to-use potential and because of the large panel of mutants (sek-1 or daf-16::gfp mutants for example), C. elegans appears an efficient in vivo model that could be used for the screening of microorganisms collections with the aim to identify new potential probiotic strains and to investigate the molecular mechanisms involved. The potential probiotic capacities of new strains need the use of different and complementary approaches to be elucidated. 


\section{C. elegans: MODEL LIMITATIONS AND PRACTICAL INTERPRETATION PITFALLS}

Like all study models, the C. elegans nematode is not without limitations which could bias the interpretation of the results obtained (39). From a practical point of view, although the worm is rather easy to use, its total control requires a significant training. Some crucial experimental points can be quite tricky such as synchronization step or daily worms counting on solid medium spread with yeasts for example; in the absence of an automated system, its implementation is particularly timeconsuming. The cell number of the worm is anyway limited (20 intestinal cells out of 959 cells for an entire worm) questioning about the relevance of the phenotypes observed and their extrapolation to humans which are composed of many different and complex tissues. In addition, the impossibility of maintaining it at $37^{\circ} \mathrm{C}$ is an important limit since it can greatly affect the metabolism of the microorganisms studied. This makes it tricky extrapolating the results to humans. Moreover, the main way to provide the microorganism of interest is to feed with, which represents a risk to see them destroyed by the digestive system of the animal. Because of the worm's ability to choose its food, it is essential to ensure that the microorganism has been consumed because otherwise, the results obtained will be distorted.

In the laboratory, the nematode is conventionally propagated on axenic cultures preventing any installation of a complex microbiota within its digestive tract, which causes a drift compared to wild physiological conditions. In addition, the absence of an adaptive immune system and a variable correlation of virulence factors with mammals limit the scope and extrapolation of the experimental results.

Nevertheless, an objective critical analysis of the advantages and disadvantages of the animal still makes it possible to demonstrate that this model is suitable for carrying out preclinical tests intended for a future application in human. Indeed, the nematode represents a good intermediary between in vitro cell cultures and mammals. Compared to cell cultures, $C$. elegans has the obvious advantage of being an entire organism with different cell and tissue structures, which the in vitro approach does not or hardly allow. Because of the absence of ethical problems and of a lower cost, it allows a more precise orientation of future experiments on mammals decreasing at the same time the number of animals to use and/or sacrifice.

\section{PROBIOTIC MICROORGANISMS INFLUENCE ON C. elegans LIFESPAN}

Safety assessment is a mandatory to characterize the innocuity of any probiotic stains. In this context, one of the in vivo strategy to be considered is the study of the survival of the nematode (83).

\section{Positive and Negative Effects of Probiotics on the Worm Lifespan}

As most living organisms, the nutrient sources used for the growth and propagation of $C$. elegans have a direct impact on its health, its defenses against pathogens and its lifespan (84).
Studies showed that the worm lifespan is increased when it is propagated on axenic cultures (85), or on agar medium with UV-killed bacteria $(86,87)$. Moreover, C. elegans fed with some probiotics showed a lower bacterial load in its intestine than those fed with E. coli OP50, allowing an extension of the worm's lifespan (88). The behavior of C. elegans in contact with probiotic microorganisms, which are supposed to improve the health of the host, needed investigation.

Focusing on Lactic Acid Bacteria (LAB), some lactobacilli strains significantly increase C. elegans N2 (wild type) mean lifespan compared to conditions where it is fed with the standard food E. coli OP50. Ten lactobacilli strains ( $L$. fermentum, L. gasseri, L. helveticus, L. paracasei, L. plantarum, and $L$. rhamnosus) and two bifidobacteria strains (B. infantis and B. longum) (Figure 1A) have been shown to increase nematode survival of C. elegans wild-type N2 from $17 \%$ to a maximum of $46 \%(11,34,36,76,89-91)$. Other studies showed that Lactobacillus (L. helveticus, L. plantarum, and L. rhamnosus) or Bifidobacterium (B. infantis and B. longum) grown under anaerobic conditions, also allowed the increase of $C$. elegans longevity with respectively $25,22,33,29$ and $17 \%$ of augmentation $(27,84)$. It has been shown that the significant increase in C. elegans survival by Lactobacillus gasseri SBT2055 occurs with both live bacteria and UV-killed bacteria. This potentiation was correlated with the ratio $E$. coli OP50/L. gasseri LG2055 used, i.e., the smaller the ratio the larger the survival rate (86). A recent study has shown an increase in longevity and an improvement in the physical functions of the host when it is fed with heat-killed probiotic strains (L. paracasei D3-5 and $L$. plantarum SK-9). According to the authors, these properties are associated with an anti-aging effect by maintaining high muscle mass and normal body size (91). Another study showed that a mix of B. infantis and E. coli OP50 at different proportions influenced the longevity of the worm. This information shows that it is necessary to consider the quantity of microorganisms brought to the nematode, especially the proportions in the case of a mixture, to make rigorous experiment and obtain relevant data. Also, it should be noted that the food used routinely for the maintenance of worms can have an impact on the way the worm responds to a biotic or abiotic stress. From where, there is an interest to use E. coli OP50, known to have little effect in $C$. elegans and should be always used as a control condition during experiment. Considering all these studies, we noticed that LAB strains exert a positive effect on the worm lifespan either alive or dead or both. Further investigations are needed to understand why this point influence the beneficial effect of a strain. It could be a strategic data to include in the process of development of new LBP. The authors agreed to suggest that the mechanism used by the bacteria to promote the longevity of the worm involves the p38 MAPK (i.e., p38 Mitogen-Activated Protein Kinase) signaling pathway until the induction of the expression of skn1 gene and the target genes of SKN-1, encoding the antioxidant proteins (phase 2 detoxification enzymes) (86). They have also found that the cell wall (lipoteichoic acids) of Bifidobacteria plays a key role in increasing the longevity of nematodes, which is in a good correlation with other works focused on B. longum $(93,94)$. Another study showed the stimulation of C. elegans 


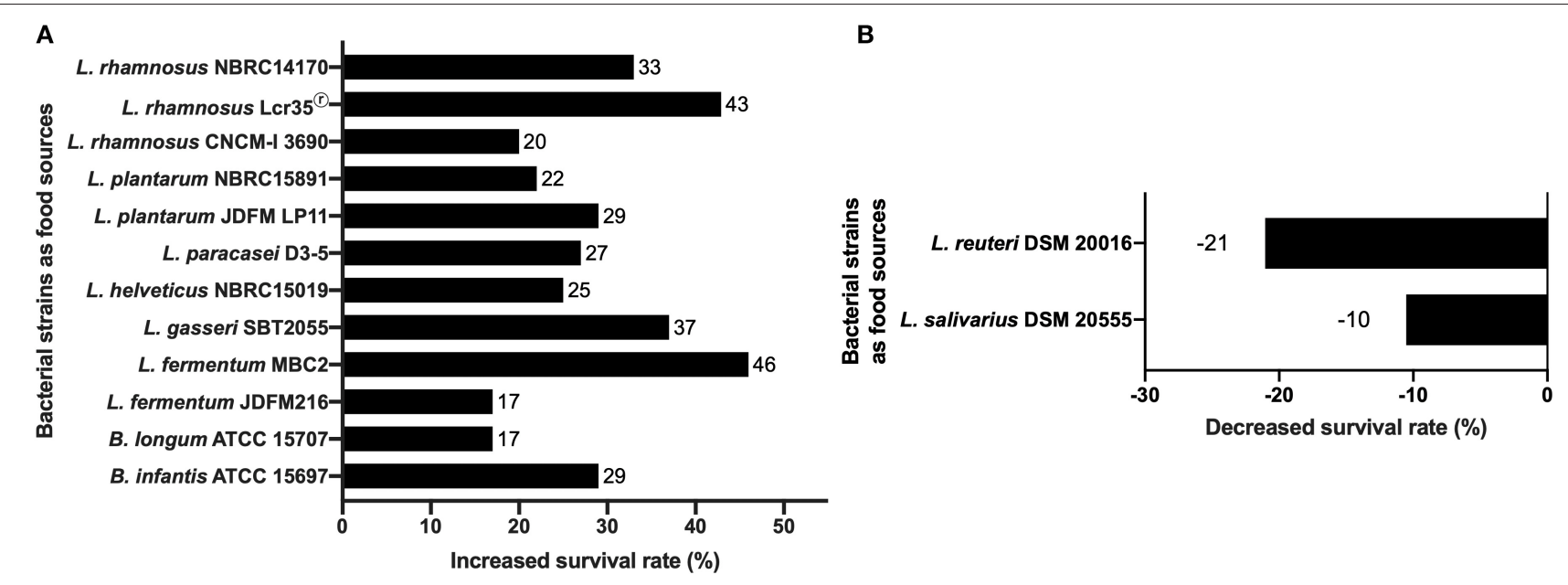

FIGURE 1 | Effects of bacterial probiotic strains on C. elegans lifespan. (A) Lifespan of C. elegans N2 fed with lactic acid bacteria compared to worms fed with E. coli OP50. The increase in the survival rate is represented for each strain as a percentage of the survival rate of $C$. elegans fed on $E$. coli OP50

$(11,27,34,36,76,84,89-91)$. (B) Negative effects of $L$. salivarius and $L$. reuteri on $C$. elegans lifespan. The decrease in the survival rate is represented for each strain as a percentage of the survival rate of $C$. elegans fed on $E$. coli OP50 (92). The decrease in the survival rate is represented for each strain as a percentage of the survival rate of $C$. elegans fed on $E$. coli OP50.

longevity through pmk-1 and nuclear hormone receptor (NHR), a receptor family associated with longevity in humans and animals, including C. elegans, even if the underlying mechanism in human remains unclear (95). Recently, the authors have shown that a mutation of the Toll-like receptor homolog TOL-1 in the nematode induced a significant increase in longevity of the host in the presence of $B$. infantis, but not in the presence of Bacillus subtilis nor Clostridium butyricum. In addition, the tol-1 mutants exhibited reduced leaving behavior from the B. infantis lawn (96).

Similarly, daf-2 [long-lived strain (97)] or daf-16 C. elegans [short-lived strain (98)] mutants have been shown to have an extended lifespan similar to wild-type $C$. elegans when fed with $L$. gasseri LG2055. The mechanism allowing the increased lifespan seems independent of DAF-2 or DAF-16 since their expression as well as the expression of related genes age-1, skn-1, sek-1, and pmk-1 remained stable in these conditions. However, the phosphorylation level and consequently the cellular localization (cytoplasm or nucleus) of the transcription factor DAF-16, nor the expression of the DAF-16 regulated genes have been characterized (86).

The work of Fasseas et al. showed that some strains of LAB could have a negative impact on the lifespan of the worm (Figure 1B). Adult C. elegans N2 worms fed with live bacterial cells belonging to the species Lactobacillus salivarius and Lactobacillus reuteri showed a significant reduction in their mean lifespan compared to those fed with E. coli OP50 with an average of 17,15 , and 19 days respectively. However, alive $L$. salivarius has the ability to restore a normal lifespan to short-lived C. elegans daf-16 mutant (92) suggesting an impact of this specie to counterbalance the lack of DAF-16 function in longevity. Sugawara et al. showed that worms fed with killed B. longum in addition to E. coli OP50 displayed reduced worm's longevity in a B. longum dose-dependent manner. Moreover, aging worms fed with only killed B. longum displayed longer life span than those fed E. coli alone. This study revealed that killed B. longum effects in C. elegans were mediated by DAF-16 nuclear localization leading to the overexpression of DAF-16 target genes (99). These findings are in contradiction with previous observations with different Bifidobacterium and Lactobacillus strains, which showed the role for SKN-1 independently of DAF-16 (99).

Although these LAB strains have a negative impact on the wild worm's lifespan, an antitumor role in C. elegans gld-1 $1^{-/-}$mutant has been demonstrated. The lack of gld-1, coding for a tumor suppressor, causes the anarchic multiplication of cells, filling the body of the worm until its death. When adult $\mathrm{gld}-1^{-/-}$worms are fed with $L$. salivarius or $L$. reuteri, a significant inhibition of tumor cells growth is observed with both alive and UV-killed bacteria $(92,100)$. Until now, the antitumor mechanism of LAB has not been elucidated even if their role in modulating the intestinal microbiota would protect against the development of colorectal cancer $(101,102)$. These data suggest that C. elegans could be used as a "living laboratory" for the study of antitumor properties of LAB or other probiotics.

Although there are both probiotic species with positive effects $(11,86,93)$ and others with negative effects (92) on C. elegans lifespan, there are also some that have no significant effect on the nematode lifespan. These species include, for instance, Lactobacillus helveticus JCM1120 ${ }^{\mathrm{T}}$ (86) or UV-killed Pediococcus acidilactici (92). Considering broader probiotic strains, Kato et al. showed that both living and UV-killed C. butyricum MIYAIRI 588 extends the lifespan of $C$. elegans through regulation of the insulin/IGF-1 signaling (IIS) pathway and the Nrf2 transcription factor. It improves resistance to several stresses in C. elegans such as infections with pathogenic bacteria ( $S$. enterica and $S$. aureus), UV irradiation, and the metal stressor $\mathrm{Cu}^{2+}$ (87). Two other bacteria from human intestine and displaying probiotic capacities, Butyrococcus pullicaecorum and Megasphaera elsdenii, extend the lifespan of $C$. elegans via the transforming growth 
factor-beta (TGF- $\beta$ ) pathway associated with anti-inflammatory processes in the innate immune system (103).

It has been demonstrated by Garsin et al. that the culture medium used for bacterial growth had a significant importance on the viability tests. E. coli cultured on brain heart infusion broth (BHI) leads a fast mortality to the nematode with a lethality time 50\% (LT50) of only 6 days whereas it is not particularly pathogenic on Nematode Growth Medium (NGM). The authors also stated that two other species, Enterococcus faecium and Streptococcus pyogenes, do not show any significant worm mortality on BHI whereas this may be the case using NGM (33). Even if it is the only published work on this subject, this critical experimental point must be considered when working on the probiotic effect of microorganisms.

Although represented in an ultra-majority by lactobacilli and bifidobacteria, probiotics should not be limited to only prokaryotes. Indeed yeasts can also play this role. The recent study by Veisseire and colleagues has thus demonstrated, in $C$. elegans, the probiotic properties of the cheese yeast Debaryomyces hansenii Dh25 (104). The authors showed that in its presence, the nematode had a significantly increased life expectancy and was able to resist to a $S$. Typhimurium UPsm1 infection. Additional studies are nevertheless necessary to characterize the mechanisms involved. However, such studies are promising since it strengthens the antipathogenic arsenal represented by probiotics.

Nowadays, although the health benefits on higher animals by probiotics are indisputable, there is no proof of an improvement of the life expectancy induced by these microorganisms except with the nematode (84). Considering that the pathways that influence aging and longevity are well-conserved among eukaryotic species from yeast to mammals, including C. elegans $(105,106)$, the use of this model to evaluate the potential benefits of microorganisms on human health during aging and longevity and to understand the host-microorganisms interactions is promising. The Insulin/IGF-1 signaling (IIS) pathway is in the focus of discussions concerning C. elegans longevity and health span. Further investigations are needed to determine if long-lived worms with reduced IIS (daf-2 mutants) enjoy a better health related to their extended lifespan and to understand how is aging delayed in C. elegans. Even if the C. elegans-E. coli OP50 binary model does not show the same relationship than human share with its microbiota complex community, it allows the study of bacterial species for their direct or indirect role in the nematode physiology and longevity. C. elegans offers the possibility of carrying out screening tests on collections of microorganisms to envisage the selection of new strains with probiotic potential. These new knowledge would allow the setting up of mechanistic hypothesis for further investigating in mammalian models or on human and of new paradigms applicable to more complex organisms such as humans (107).

\section{Mechanisms and Pathways Implied for Worm Longevity}

In C. elegans, the regulation of life expectancy mainly involves at least three signaling pathways: DAF-2/DAF-16 (insulin-like signaling pathway), p38 MAPK, and JNK pathways. In the DAF2/DAF-16 pathway, activation of the DAF-2 transmembrane receptor induces a phosphorylation cascade via AGE-1/PI3K (phosphoinositide 3-kinase) and the Serine-Threonine kinases (PDK-1, AKT-1, AKT-2) which regulates the DAF-16/FOXO transcription factor by phosphorylating it. When DAF-16 is dephosphorylated, it is translocated into the nucleus where it activates the transcription of genes involved in lifespan control (108).

The p38 MAPK (also called PMK-1) pathway is activated through phosphorylation by upstream MAPKK (SEK-1), which is activated by MAPKKK (NSY-1). It has a role in regulating life expectancy by modulating the specific immune response of the worm and has been shown to be required in its resistance to bacterial infection (109). Under the control of PMK-1, potential antimicrobials are secreted such as C-type lectins, ShK toxins, or CUB-like genes in response to $P$. aeruginosa infection. In addition, a complete genome expression analysis suggests that the DAF-2/DAF-16 and p38 MAPK pathways are two distinct pathways since they do not positively regulate the same genes at the same time (29). Another study showed that PMK-1 contributes to the increased longevity of daf-2 mutants and that this increased longevity was mediated by DAF-16 via the upregulation of antimicrobials (110). PMK-1 may play a similar role via distinct immune effectors to enhance lifespan suggesting that innate immunity is a key determinant of longevity. Because immunity is tightly associated with human longevity as well, further characterizing the interplay between immunity and longevity in C. elegans may provide us new insights into the mechanisms of human aging and age-related diseases.

The JNK (c-Jun N-terminal Kinase) pathway is activated by cytokines and in response to stresses such as UV irradiation, Reactive Oxygen Species (ROS), DNA damage, heat stress, and inflammation $(111,112)$. In C. elegans, this pathway evolves in parallel with the insulin signaling pathway till it converges to DAF-16 which is phosphorylated by JNK-1 $(28,113)$. The activation of JNK-1/DAF-16 signaling pathway leading to the overexpression of sod-3 (superoxide dismutase) gene has been shown to be activated by $B$. longum $\mathrm{BB} 68$ to increase the longevity of the nematode (94).

In the case of $B$. subtilis NCIB3610, several mechanisms explaining its beneficial effects on $C$. elegans have been proposed. It has been found that one of the key conditions to promote longevity of the worm was the formation of a biofilm in the intestinal environment. The expression of bslA gene and the tapA-sipW-tasA and epsA-G operons, encoding essential components to the biofilm formation (Hydrophobin, TasA protein, and the EPS exopolysaccharide, respectively), were identified as necessary for extending the worm's longevity (114). The second mechanism is based on the use of bacterial nitric oxide (NO) to mediate lifespan extension via the expression of a group of genes that function under the dual control of HSF-1 (an activator of heat shock proteins) and DAF-16 transcription factors (115). C. elegans, which is unable to synthesize NO because it lacks NO synthase, uses the one produced by the bacteria to regulate its own metabolism $(114,116)$. NO provides better thermotolerance due to activation of HSF-1 (115). Another 
study focused on Lactobacillus fermentum MBC2 highlighted the role of fat metabolism in C. elegans viability, further supporting the strong correlation between reduction of fat storage and extension of lifespan in nematodes. They showed a PEPT-1dependent pro-longevity effect, mediated by the transcriptional factor DAF-16; pept-1 gene is one of the major regulators of fat content in C. elegans (76). The measure of the ratio of lipids and proteins in the worms could be informative to evaluate the potential beneficial effect of a LAB strain on its lifespan.

Recent studies suggested a key role of bacterial quorum sensing molecules in the repression of $C$. elegans infection with the pathogens Candida albicans or P. aeruginosa, showing that the nematode can detect microbial signals and develop a symbiotic interaction $(117,118)$. The quorum-sensing pentapeptide CSF (Competence Sporulation Stimulating Factor) of $B$. subtilis has been shown to play a role in the extension of the nematode longevity (114). B. subtilis CSF was reported to contribute to intestinal homeostasis of the host by activating the p38 MAPK survival pathways and by inducing the synthesis of cytoprotective heat shock proteins (HSPs) $(119,120)$. The nematode survival may be due to quorum sensing molecules such as NO and CSF and to biofilm formation (114).

All this data highlighted the idea that LAB strains can exert a beneficial effect on C. elegans via several specific mechanisms and pathways. C. elegans can be considered as a pertinent model for the screening of potential lifespan enhancing probiotics and their anti-aging compounds.

\section{PROTECTIVE EFFECTS OF LAB AGAINST ABIOTIC STRESS IN C. elegans}

The environment in which C. elegans evolves can be the source of abiotic stress (oxidative, thermal) having a harmful effect on the physiology of the animal. The scientific community has therefore wondered if the administration of LAB could allow the nematode to survive to these stresses with the aim to further understand the mechanisms involved in abiotic stress-resistance.

\section{Reactive Oxygen Species and Hormesis}

ROS are responsible for oxidative damage to proteins, lipids as well as to nucleic acids leading to severe mutations in DNA $(121,122)$. A close association exists between ROS generation, ROS-related damage and aging (123). Reducing the amount of Reactive Oxygen Species (ROS) is essential to maintain a good health in most living organisms. In some model organisms such as the yeast Saccharomyces cerevisiae, the fly D. melanogaster or the worm C. elegans, low doses of ROS seem to induce promotion of health and lifespan whereas higher doses are deleterious $(76,124)$.

This phenomenon i.e., the biphasic response to a potentially harmful compound, firstly described in 1943 by Southam and Ehrlich (125) under the name of hormesis, then to mithormesis (i.e., mitochondrial hormesis), has been discovered more recently in C. elegans (126). It was shown that many of the Insulin/insulin-like growth factor signaling pathway genes had a role in hormetic processes, either in response to heat stress (e.g., daf-3 and daf-5), or in lifespan extension (e.g., daf-12 and daf-16) or both (daf-18) (Figure 2). Regarding the worm, the study was focused on gene expression and thus the physiological and metabolic effects arising from thermal stress remain uncharacterized. A study showed that ROS signals are transduced mainly by the oxidative stress transcriptional factors SKN-1 (Nrf2 or NFE2L2 in mammals) and JUN-1, and partially by DAF-16. Cell biology experiments demonstrated a similarity between human DUOXs and C. elegans BLI-3 dual oxidases, suggesting that DUOXs are potential targets of intervention for lifespan extension. They suggest that low levels of ROS, fine-tuned by the peroxidase and dual oxidase, act as second messengers to extend lifespan by the effect of hormesis (127).

\section{Oxidative Stress}

One of the indicators of the presence of a possible oxidative stress is the reduced glutathione form (GSH)/oxidized form (GSSG) ratio. Under normal physiological conditions, the reduced form predominates, in order to be subsequently oxidized by ROS if necessary (128). L. gasseri SBT2055 is at the origin of a 3fold increase of the GSH/GSSG ratio compared to E. coli OP50 condition. Combining the increase in SOD activity and a greater amount of reduced glutathione, L. gasseri SBT2055 has been shown to play an important role in reducing ROS and damage related to oxidative phenomena (86).

L. gasseri SBT2055, a lactic acid bacterium previously mentioned for its ability to increase the lifespan of the nematode, also allows the host organism to fight effectively against oxidative stress. Analyses of 10-day-old adult worms fed with L. gasseri SBT2055 showed a significant overexpression of sod-1 gene and an $80 \%$ increase in superoxide dismutase activity compared to worms fed with E. coli OP50 as well as an enhanced activity of the Nrf-2 ortholog SKN-1. The same molecular anti-oxidative mechanism has been identified in mammalian cells, protecting cells against oxidative stress (129). Many other genes have been reported to have significant over-expressions such as trx1, $c l k-1, h s p 16.2$, or $g c s-1$ respectively encoding a thioredoxin, a mitochondrial polypeptide, a heat-shock protein and an ortholog of the $\gamma$-glutamyl-cysteine synthetase (86).

L. rhamnosus CNCM I-3690, in addition to its beneficial effects of the worm's lifespan, gives C. elegans a protection against oxidative stress. This strain causes activation of DAF16 transcription factor, which subsequently induces an increased longevity, a decrease in the amount of lipid inclusions and an increased resistance to hydrogen peroxide. These three effects are the result of the reduction of the inflammatory process. In addition, similar results were observed in vitro using dendritic cells culture where L. rhamnosus was actively involved in reducing pro-inflammatory cytokine ratios such as IL12/IL10, IL6/IL10, IL8/IL10, and TNF $/$ IL10 (11). Another study showed that worms fed with killed B. longum in addition to E. coli OP50 had a higher survival rate, compared with worms fed $E$. coli alone, following hydrogen peroxide-induced oxidative stress and heat stress at $35^{\circ} \mathrm{C}(99)$. 


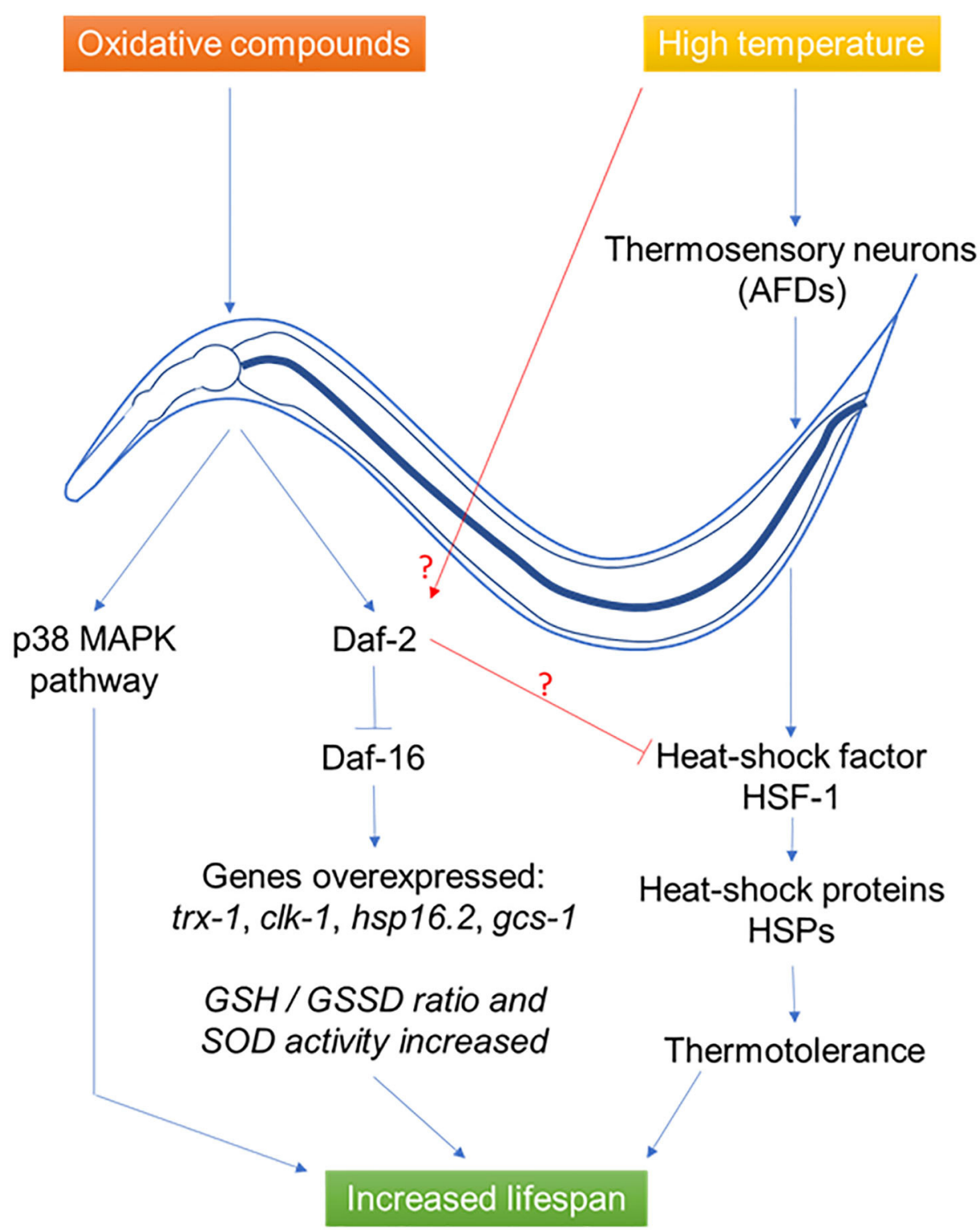

FIGURE 2 | Effects of probiotics L. gasseri SBT2055 (86), L. rhamnosus CNCM I-3690 (11), B. longum (99), and B. subtilis NCIB3610 (114) on C. elegans during abiotic stress. During oxidative stress, the bacteria induce a response in the host via the p38 MAPK and DAF-2/DAF-16 pathways allowing the synthesis of antioxidant metabolites. In the case of thermal stress, a neural response induces the synthesis of heat-shock proteins to allow thermotolerance. In both cases, the result is an increase in the longevity of the host.

\section{Heat Stress}

C. elegans, like most living species, is sensitive to temperature and can set up various defense strategies. A whole range of highly conserved genes, under the control of the two thermosensory neurons (AFDs), are activated (130) to restore cellular homeostasis when the organism detects a rapid rise in temperature (131). The lactic acid bacteria L. gasseri SBT2055 allows significant resistance of $C$. elegans to heat stress, without the underlying mechanism being evoked (86).

B. subtilis, although not part of the lactic acid bacteria group, possesses interesting probiotic capabilities. A recent study concerning C. elegans resistance against heat stress showed that the strain B. subtilis NCIB3610 induced a lifespan $132 \%$ higher on average compared to worms that were fed with standard E. coli OP50 strain. Similar results have also been observed in the case of osmotic and heavy metal stresses (114).

Concerning these abiotic stresses, some authors hypothesized that the probiotic may have a similar effect in mammals but, even if signaling pathways are well-conserved, the possibility to extrapolate this data from nematodes to mammals has to be investigated $(11,129,132)$. 


\section{INFLUENCE OF LAB ON C. elegans IMMUNITY}

The protection of an organism against a pathogen, whether it be a mammal, a bird or a nematode, involves highly conserved signaling pathways (110). In C. elegans, two major signaling pathways (Figure 3) are involved in the innate immune response: the mitogen-activated protein kinase (MAPK) pathways and the Insulin/IGF1 Signaling (ILS) pathway or DAF-2/Insulin-like Receptor (DIR) (133).

MAPK pathways, considered to be the oldest transduction pathways of immunity (134), combine several types of cascades in C. elegans. The main, p38 MAPK, originally described for its action against Gram-negative bacteria, is also described for Gram-positive and fungi $(133,135)$. Two genes, essential for resistance to pathogens, have been identified namely sek-1 and nys-1, respectively coding for a MAP kinase kinase (MAPKK) and a MAP kinase kinase kinase (MAPKKK) (134). The probiotic L. fermentum JDFM216 is able to induce the over-expression of genes from C-lectin family, including clec-60 and clec-78, as well as F-box protein and NHR related genes, as a consequence of PMK-1 signaling activation (34). Therefore, it seems that this bacterium can induce an immune response in the nematode during a possible infection. It has been shown that p38 MAPK is involved against cytolytic pore-forming toxins such as Bacillus thuringiensis Cry5B toxin (136).

The second main pathway, the DAF-2/Insulin-like receptor (DIR) pathway involving the transcription factor DAF-16, also plays a major role in the immune response although this is not fully understood (133). Transcriptomic analysis revealed DAF-16 promoted the expression of genes linked mainly to longevity and to defense against pathogens $(137,138)$.

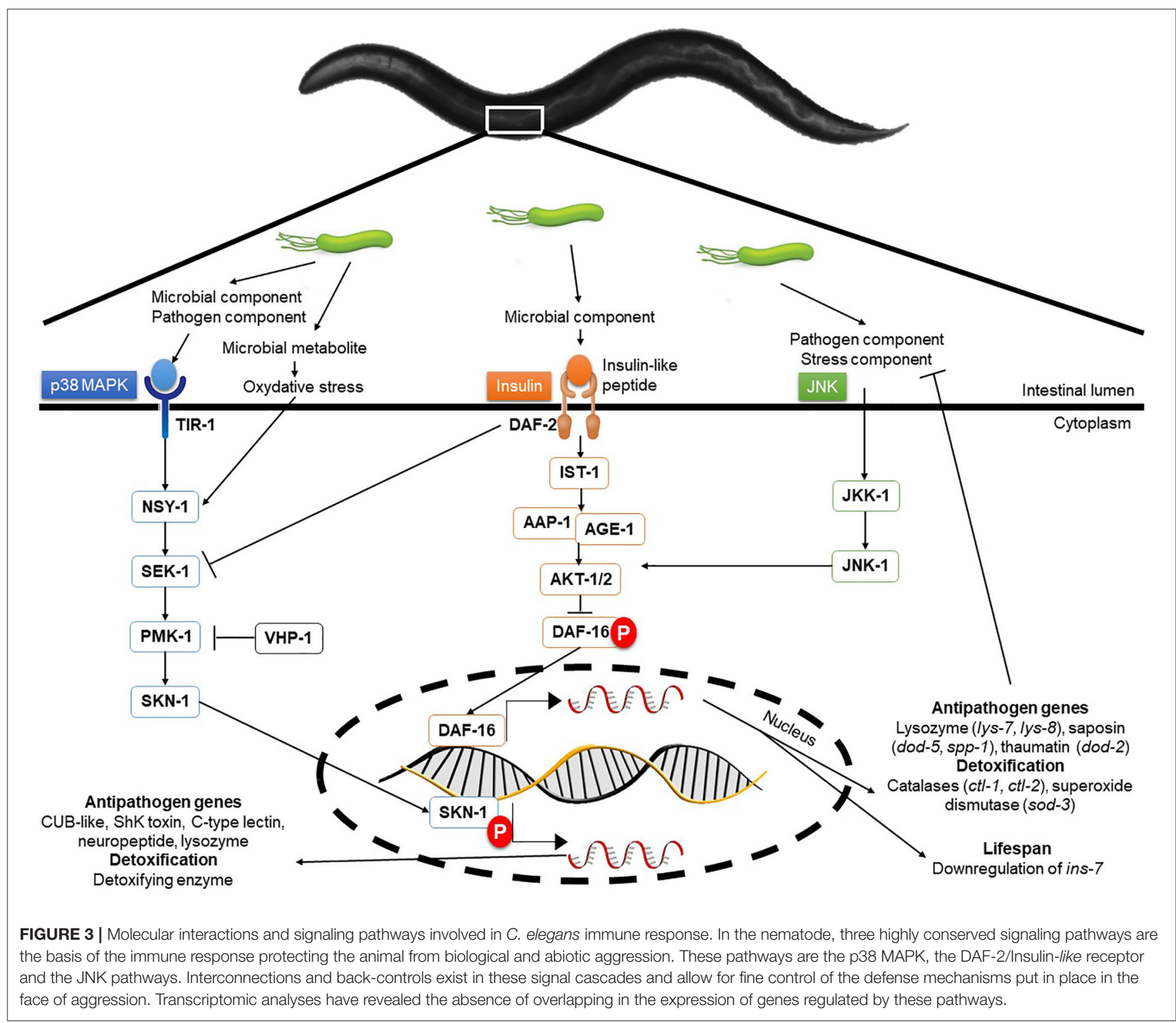


Parallel to the DAF-2/DAF-16 pathway, the c-Jun N-terminal kinase (JNK) pathway is activated by environmental stresses and inflammatory cytokines and acts as a molecular sensor for the pathway DAF-2/DAF-16 (139). Some constituents of the cell wall of lactic acid bacteria, such as muramyl dipeptide (molecule on the basis of the parietal peptidoglycan), are involved in the activation of the immune response and in particular the synthesis of cytokines (TNF $\alpha$ and IL-1 in mammals) by immunocytes (84). These cytokines are activators of c-Jun N-terminal kinase (JNK) pathway, which is a DAF-16 positive regulator (113).

C. elegans presents different transcriptional responses depending on the fungal or bacterial infection origin $(116,140)$. The genes fil-1 and clec-71, respectively encoding for a lipase and a C-type lectin are upregulated by both $P$. aeruginosa and $S$. aureus but not by C. albicans. Gram-positive and Gramnegative bacteria also induce a separate response i.e., in the presence of $P$. aeruginosa, there will be an overexpression of crp-3 (peptidase), cyp-35A2, and cyp-35C1 (cytochrome P450) genes while in the presence of $S$. aureus, $p m p-1$ (ABC transport), gst-28 (glutathione S-transferase), and lys-5 (lysozyme) genes are overexpressed. There is a common immune response to all three genera Candida, Staphylococcus, and Pseudomonas including the induction of the far-7 (nematode fatty acid retinoid binding) and cyp-37B1 (cytochrome $\mathrm{P} 450$ ) genes whereas sams-1 (S-adenosylmethionine synthetase), acdh-1 (acyl-CoA dehydrogenase), and nhr-114 (ligand binding domain of nuclear hormone receptor) genes are repressed $(116,140)$. Another study showed that $n h r-86$ induces innate immune defense independent of the p38 MAPK pmk-1 in response to $P$. aeruginosa (141). Finally, a study demonstrated that $C$. elegans response to infection by $B$. thuringiensis showed significant profile changes at the level of proteome, such effect being under the influence of AMP-activated protein kinases (AMPKs) which were supposed to be regulators of the worm immune response (82). C. elegans has neither phagocytic cells nor an adaptive immunity. Comparing to human, the single toll-like receptor does not seem to play a role in the immune response and the nematode has no NF-кB-like factor (34, 142). Anyway, because of the great conservation of the signaling pathways involved in innate immunity across species, C. elegans could be a tool of interest for the molecular characterization of immune pathways. Complementary approaches such as the use of $C$. elegans mutants and transcriptomic will allow the analysis of the immune pathways that are modulated by LAB.

\section{LAB ANTI-PATHOGEN EFFECTS}

In nature, C. elegans is found in numerous ecological niches and is likely to be host to yeasts like Candida or to bacteria such as Pseudomonas, Enterococcus (116), Micrococcus luteus, Bacillus megaterium (143), or Comamonas aquatica (144). The greater majority of worms have their intestine colonized by bacteria, especially those fed in vitro with E. coli OP50, as early as 2 days of adulthood (145).

S. enterica serovar Enteritidis, a pathogenic enterobacterium for humans, is capable of inducing mortality in C. elegans in just a few days (40\% in 5 days) after invading its intestine. However, the young adults (3 days) are resistant both to the colonization of their intestine by Salmonella and to its pathogenicity compared to the 5-day-old worms. A resistance to infection was highlighted in elderly adults (7 days) fed with probiotic bacteria (L. helveticus, L. plantarum, L. rhamnosus, $B$. infantis, and B. longum) before infection by the pathogen. It is interesting to note that the pathogenicity of $S$. Enteritidis in the nematode requires alive bacteria; otherwise, C. elegans has a lifespan quite like that encountered with E. coli OP50. L. rhamnosus, plantarum, and helveticus have been reported providing a much better resistance to $S$. Enteritidis infection in the worm without limiting its presence in the intestine. Consequently, the mechanism of inhibition of the virulence of $S$. Enteritidis would not be due to the synthesis of antimicrobial compounds but rather to a certain immunotolerance (84). Rangan et al. showed that the antigen A SagA secreted from E. faecium is sufficient to promote pathogen tolerance in a tol1 dependent manner, protecting C. elegans against Salmonella pathogenesis (132). This protective activity has been observed in mice as well. In worms fed E. faecium L11, the increased expression of genes related to the MAPK pathway ( $p m k-1$ and sek-1) and to the TGF- $\beta$ pathway ( $d b l-1$ and sma-3) was shown to contribute to the resistance against Salmonella infection (35). Lysozymes, such as LYS-8 which is under the control of $d b l-1$ and sma-3, and lectins were identified as antimicrobial peptides that help to nematode defense against infection (146). Recently, a study has focused on the antimicrobial properties of the probiotic strain E. coli Nissle $1917(\mathrm{EcN})$ against infection by enteropathogenic E. coli (EPEC). The authors showed that $\mathrm{EcN}$ inhibited the pathogenicity of EPEC by competitive colonization of C. elegans intestine. In addition, they also demonstrated that $\mathrm{EcN}$ enhances the integrity of the intestinal barrier via the induction of Zonula occludens ortholog (Zoo-1), a tight junction protein (147). A transcriptomic study showed that Pediococcus acidilactici P25 affects the expression of genes relative to innate immune response, peroxisome, longevity, and MAPK pathways and reduced the gut colonization of the worm and the expression of enterotoxin genes by E. coli ETEC K88 (148). In addition, the work of Chelliah and colleagues has shown the benefit of using antimicrobial peptides isolated from the cell-free supernatant of Pediococcus to treat bacterial infections. Indeed, after preincubation with a molecule produced by $P$. acidilactici and molecular weight lower than $3 \mathrm{kDa}$ (pediocin), nematodes showed increased survivals facing E. coli O157 and Helicobacter pylori infections. This increased survival was also associated with a significant decrease in the bacterial load in the gut of the worms (149).

The pathogen $C$. albicans ATCC ${ }^{\circledR} 10231^{\mathrm{TM}}$ can induce a $100 \%$ mortality in C. elegans in 3 days. L. rhamnosus Lcr35 ${ }^{\circledR}$, in addition to having a pro-longevity activity, protects the worm from a C. albicans infection ( $+267 \%$ of survival) even if the yeast is still detectable in its intestine. At the mechanistic level and during a preventive treatment, genes of the p38 MAPK signaling pathway are repressed and genes involved in the antifungal response are induced by $\operatorname{Lcr} 35^{\circledR}$, suggesting that the pathogen appears not to be detected by the worm immune system. 
However, the DAF-16/FOXO transcription factor, implicated in the longevity and antipathogenic response of C. elegans, is activated by $\operatorname{Lcr} 35^{\circledR}$, suggesting that the probiotic strain acts by stimulating its host via DAF-16 but also by suppressing the virulence of the pathogen (90). However, in a second study, the authors showed for the first time the effectiveness of a Live Biotherapeutic Microorganism (i.e., L. rhamnosus $\operatorname{Lcr} 35^{\circledR}$ ) in a curative context against candidiasis and a different mechanism of actions with, the activation of the p38 MAPK pathway in the nematode (150). It has been also demonstrated that molecules involved in bacterial quorum-sensing such as indole and its derivative, indole-3-acetonitrile (IAN) were able to significantly alleviate the virulence of $C$. albicans in C. elegans reducing the fungal burden in the intestine (118). In another study, a clinical isolate of $L$. paracasei increased the survival of C. elegans infected with C. albicans by $29 \%$. This prolonged longevity was accompanied by the inhibition of filamentation of C. albicans ATCC $^{\circledR} 18804^{\mathrm{TM}}$, preventing the cuticle rupture of the worms of $27 \%$. A negative regulation of the tec 1 and ume 6 genes that are essential for the production of hyphae was suggested to explain the reduced filamentation of C. albicans (151). However, the authors have not demonstrated the effect of $L$. paracasei on the immune response of the nematode.

With regard to colonization of the intestine, the prerequisite that one condition for a microbial strain to be recognized as probiotic is its ability to colonize the gut (if used orally) is controversial $(152,153)$. In spite of the fact that L. gasseri SBT2055 had undeniable positive effects on the worm and that its presence in its intestine had been confirmed, it is unable to colonize it (86). It would be of interest to follow L. gasseri STB2055 population to specify whether it constitutes a transient microbiota or if it is destroyed in the digestive tract. It has also been shown that L. plantarum, as well as L. zeae LB1 and L. casei CL11, was able to colonize the C. elegans intestine and to remain on it over $4.3 \mathrm{CFU} / \mathrm{mL}$ per worm (this is higher than $3.2 \mathrm{CFU} / \mathrm{mL}$ per worm obtained with L. rhamnosus GG), thereby contributing to the inhibition of $S$. aureus by stimulating the innate immune system but the underlying mechanisms are not clearly defined (74). Another study evaluating 15 probiotic strains including $L$. plantarum K90 and L. paracasei CD4 that exhibited increased nematode lifespan showed that gut colonization ability differs among the strains tested (154). The last study of Sharma suggests that the adhered probiotic strains inhibit the attachment of $E$. coli pathogenic strains on the intestinal layer of C. elegans, blocking receptors sites and reducing pathogen colonization (89). A study on 35 strains of LAB showed the ability of three strains, L. brevis, $P$. acidilatici, and $P$. pentosaceus, to increase the lifespan of $C$. elegans infected with $P$. aeruginosa PA14 and to colonize the $C$. elegans gut (32). In the Ikeda et al. study, lactic acid bacteria have not been able to reduce the colonization of the intestine by the pathogen which may be the sign of the absence of synthesis of antimicrobial compounds (84). This lack of inhibition of colonization of the gut by a pathogen has also been demonstrated with enterotoxinogenic E. coli (ETEC), a deadly strain for $C$. elegans, in the presence of L. zeae LB1 and L. casei CL11. In the present case, the protection of the worm by the probiotics is due to the inhibition of the enterotoxins synthesis whose mechanism is not yet understood (155). Both lactobacilli, as well as the $L$. plantarum JDFM LP11 and the L. rhamnosus GG (36) are able to colonize the intestine of the worm and are found at the rate of $10^{4}$ to $10^{5} \mathrm{CFU} /$ worm, as much as for ETEC. The relevance of intestinal colonization for a probiotic strain to exert its optimal effect must be further characterized in the worm before to be studied in mammals and extrapolated to human.

The enterohaemorrhagic E. coli (EHEC) O157:H7 strain also exhibits significant pathogenicity to $C$. elegans, thereby reducing its lifespan compared to an avirulent bacterium. A study using the probiotic E. faecalis [marketed under the name Symbioflor ${ }^{\circledR}$ (Symbiopharm, Herborn, Germany)] showed that E. faecalis exerted a protective effect, significantly reducing the mortality of C. elegans due to EHEC. A mix E. faecalis-E. coli O157:H7 restored partly a lifespan but not as that observed with E. coli OP50 or Symbioflor ${ }^{\circledR}$ alone. It is of interest to note here the potentialization of the E. faecalis strain anti-EHEC effect by the galenic Symbioflor ${ }^{\circledR}$. This beneficial effect of E. faecalis was explained by the fact that the probiotic negatively regulates a large number of genes associated with the virulence of $E$. coli O157: H7 like espA, espB, espD (encoding for LEE structural element), or sepQ (pore forming protein) (156). However, the st $x 1 B$ and st $x 2 B$ genes both encoding for Shiga-like toxin subunits are not repressed in the presence of the probiotic (156), as was the case with $L$ acidophilus (157). The authors made the hypothesis that the inactivation of the toxin can be explained by the fact that both E. coli and E. faecalis are lysed by the grinder of the worm and that the fragments of E. faecalis inhibit the fixation of toxins on cellular receptors (156). At the early infection by enterohaemorrhagic E. coli, the p38 MAPK pathway, involved in the innate immune response is induced by Stx-1 toxin (158). In the case of L. pneumophila, it appears that when adult C. elegans is fed with B. infantis and then exposed to L. pneumophila, a significantly increased resistance to the pathogen was observed although $B$. infantis did not reduce the amount of the pathogen in the gut. This strengthening of the immune system would imply, as for longevity, the PMK-1/p38 MAPK signaling system (159).

In addition, opposite bacterial responses were highlighted. Feeding C. elegans with $L$. acidophilus will result in protecting the worm against infections of pathogenic Gram-positive E. faecalis and $S$. aureus but not against $P$. aeruginosa (160) which is a Gram-negative bacterium. Moreover, exposing C. elegans with a non-pathogenic Gram-negative bacterium, P. mendocina, will have a positive action against infections of the pathogen $P$. aeruginosa PA14 (116). All these data show that the beneficial or deleterious effect of a bacteria on C. elegans remained strain dependent leading to suggest that a characterization of the interaction mechanisms are needed. A question is then arising concerning these contradictory effects of the same strain for future applications on human health.

In conclusion concerning the anti-pathogen effects of probiotics observed in C. elegans, it looks like only part of the signaling pathways are characterized. The molecular mechanisms underlying the interactions between probiotics, pathogens and hosts have yet to be explored. Moreover, the role of probiotics gut colonization in the resistance to pathogens is not clearly evaluated and would be strain dependent. A strain-by-strain 
molecular study using complementary approaches on C. elegans appeared to be necessary to highlight the probiotic potential of a microorganism. Another application using the worm would be to test the anti-pathogen potential of microbial consortia (bacteria and fungi) rather than single microorganism. The data obtained would help us to understand the link between microbiota and health i.e., anti-pathogen effect, aging, immunity and to design strategies to fight against a large panel of pathogens. Moreover, C. elegans seems to be less susceptible than mammalian cells to antibiotic drugs targeting the lipidbilayer membrane of the pathogenic microorganism $S$. aureus $(34,142)$. This point concerning the host cell physiology has to be considered when evaluating the anti-pathogen potential of a new probiotic strain dedicated to human health. It also seems important to be interested in the impact of probiotics on the physiology (general morphology, structural integrity) of the nematode after the ingestion of these microorganisms, in a qualitative (microscopy) and quantitative way by methods of transcriptomics or proteomics (i.e., expression and translation of cuticle proteins). Finally, it is necessary, through mechanistic studies, to precisely establish the link between the immune response, the effective defense against a pathogen and other fundamental biological functions such as longevity.

\section{TRANSLATIONAL RESEARCH AND PROSPECTS}

Understanding the mechanisms of action of a microorganism in a host such as C. elegans has led to many technological and scientific breakthroughs. However, the opportunities of transposition to the human model are mandatory in order to develop therapeutic strategies dedicated to human health.

\section{The Roundworm as a Model System to Study Human Diseases}

Molecular decoding of host-microorganisms interactions mechanisms requires the implementation of in vitro and in vivo approaches to investigate their biochemical, genetic, and phenotypic components. A better understanding of genes and their interacting partners forms the foundation for translational research leading to mechanism-based therapeutic strategies (161). In absolute terms, studying humans to understand the molecular mechanisms of human disease could be considered as the ideal solution. However, Humans are poor subjects for these studies because of heterogeneous genetic backgrounds, low reproductive rate, generation times far too important for experimental studies, wide variations in gene expression, subject to strong environmental variations and experimentations on humans are unethical. To circumvent these issues, C. elegans is being exploited to decipher human biology thanks to its properties such as the availability of molecular tools and genome sequenced and annotated, the availability of a bank of mutants, crossbreeding facilities to study genetic, high reproducibility rate and homologies with humans (161). The number of human disease-related genes that share homology with $C$. elegans genes ranges from 40 to $75 \%$ (162). Even in the absence of an orthologous gene, it is likely that there are protein domains or parts of biochemical pathways in C. elegans that are sufficiently conserved to allow the extrapolation of the mechanisms from the nematode to a model of human pathobiology (163).

Although C. elegans is a bacterivorous organism, these animals are killed by a variety of human pathogens including Gram-negative ( $P$. aeruginosa, S. enterica, Serratia marcescens, Burkholderia cepacia) and Gram-positive organisms (S. aureus, Streptococcus pneumoniae, E. faecalis) as well as fungi (Candida species) $(33,84,140,150,160)$. Several studies show that many of the host resistance (e.g., antimicrobial peptides (AMPs), MAPK signaling cascades) and bacterial (and fungal) virulence factors (e.g., Pseudomonas exotoxin A, Staphylococcus V8 protease) that operate in C. elegans infection models are the same in plants, arthropods and mammals. Thus, C. elegans infection models can serve as a useful system for dissecting apart the molecular components of host-pathogen interactions. Although evolutionarily distant from humans, C. elegans and humans share many conserved cellular pathways. Using a forward genetics screen for genes that enhanced susceptibility to pathogens, C. elegans was shown to possess several welldefined MAPK signaling cassettes [including those associated with PMK-1 (p38), KGB-1 (JNK), and MPK-1 (ERK)] that are crucial for the innate immune defense (164) and are found in arthropods and mammals. Taken together, genetic mutant analysis, transcriptional profiling and biochemical studies in $C$. elegans show that MAPK signaling is one of the primordial, yet still essential, stress response pathways in eukaryotes (165). Notably, insulin and TOR pathways function in C. elegans, as in other organisms, to coordinate nutrient and metabolic state with cellular processes (166). A better delineation of these signaling pathways should enhance our understanding of innate host resistance to a range of human pathogens. Nutrition is paramount in shaping all aspects of animal biology. In addition, the influence of the intestinal microbiota on physiology is now widely recognized. Given that diet also shapes the intestinal microbiota, this raises the question of how the nutritional environment and microbial assemblages together influence animal physiology. Leulier et al. proposed an integrative framework within which to define the study of the diet-physiology-microbiota systems and ultimately link it to human health (167). C. elegans are bacterivorous that can survive on a variety of bacterial species. For C. elegans, bacteria are both diet and microbiota. These bacteria influence metabolism, life history traits and gene expression $(143,144)$.

Taken together, these studies confirmed that live whole animal screens using C. elegans could be used as a biologic platform for potential probiotic strain discovery and characterization.

\section{Challenges and Opportunities}

Most studies using C. elegans as an in vivo model concern the anti-pathogenic effect of bacterial strains that could be used to fight against human pathogens but the major challenge is now to go further insight the mechanisms involved in the antimicrobial capacities of beneficial microorganisms. These studies have been facilitated by the discoveries of natural microbes that infect C. elegans, including bacteria, fungi, and viruses. Many 
of these microbes share a common site of infection, the $C$. elegans intestine that is the way of exposure of many pathogens as in higher eukaryotes. C. elegans possesses many of the characteristics of an efficient model for the characterization of a probiotic strain and to define host-microbes and microbesmicrobes interactions. It is a powerful and easy-to-use model already used to evaluate the impact of microorganisms on $C$. elegans longevity, immunity and to study their anti-pathogen effect. It offers the opportunities to investigate link between innate immunity and aging as well as between intestinal microbiota and aging. Moreover, the C. elegans model can be used to evaluate the safety of microorganisms, evaluating its lifespan (168). The challenge to validate C. elegans as a relevant model to study strains safety is to evaluate how can be made the parallel with humans (169). C. elegans offers good opportunities to make this link because of its strong similarity between worm and human intestinal cells in terms of physiology and functionalities. This model can be used to study a large panel of pathogenic and probiotic microorganisms with the aim to further investigate human disease mechanisms. Moreover, novel approaches are needed to develop microbial cocktails targeted to restore dysbiotic states in microbiota-associated human diseases (170). In the coming years, C. elegans could be added in screening platforms for the development of new LBPs according to a strategic workflow (Figure 4). A collection of microorganisms of interest must be tested by conventional in vitro methods to select strains that meet the eligibility criteria defined in the literature. These candidates are then characterized using C. elegans and preclinical models. The final necessary step before an application in human health remains the clinical trials. Future C. elegans research objectives are to characterize the mode of action of probiotic strains to better understand their effects on humans and to develop even better live biotherapeutic products to treat a larger panel of human dysbiosis-related affections. Even though this nematode has become one of the most intensively studied models in biological research, a full analysis of its biology would warrant further integration of this information into the research approaches (171). In addition to the strain-specific approaches,

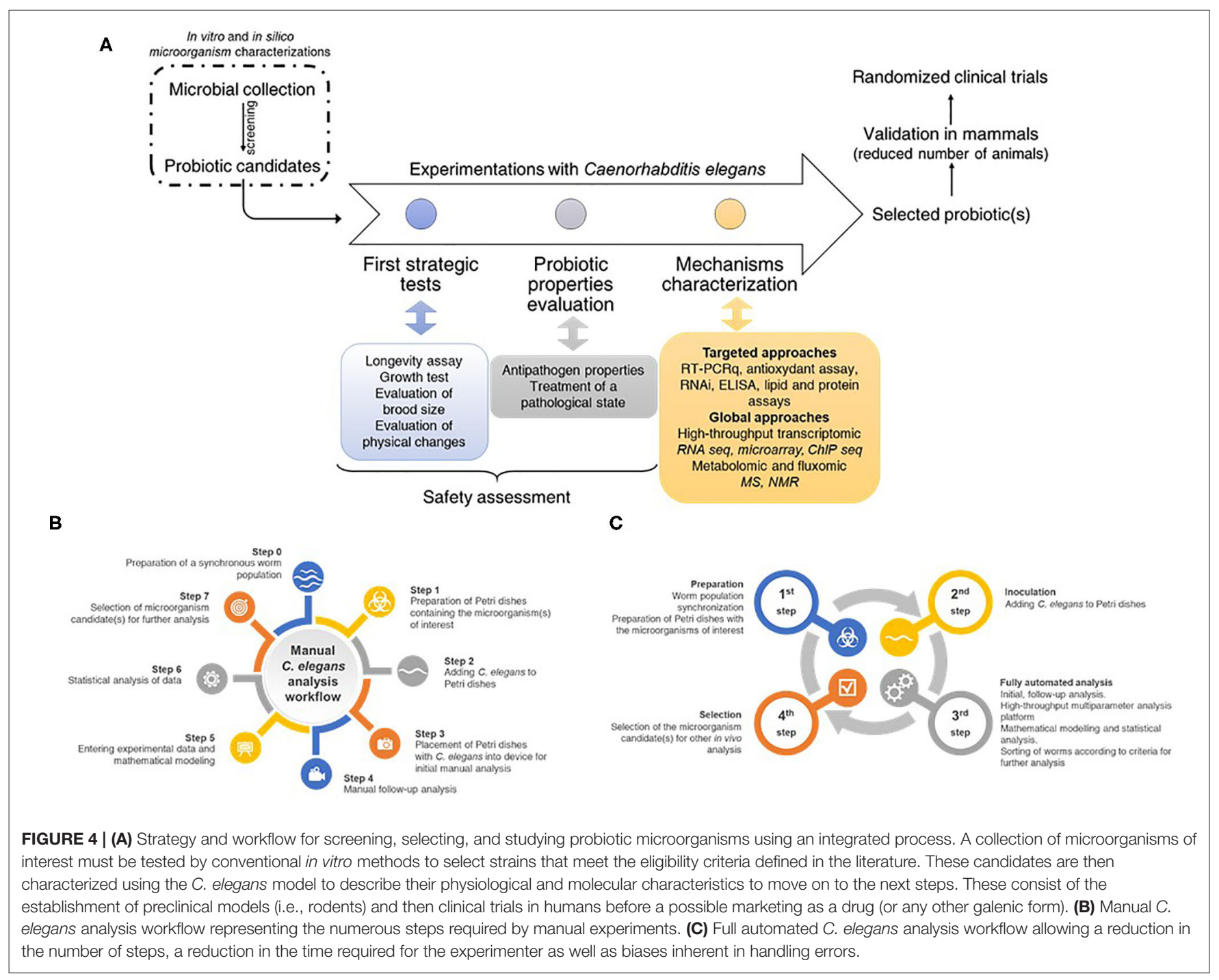


we must also take into consideration the industrial process for a large-scale production of a probiotic strain. A native probiotic strain may present different or potentiated properties depending on the culture conditions, the drying process and the galenic $(153,156,172,173)$. C. elegans could be a strategic model to test the secondary effects of new drugs (impact on its lifespan) or new formulations.

Studies using $C$. elegans as an in vivo model with the aim to characterize probiotic potential of bacterial strains are largely focused on lactic acid bacteria. Some other kinds of microorganisms such as anaerobic bacteria and fungi could be of interest as probiotics and their characteristics could be evaluated using C. elegans. Few studies have been published concerning these kinds of microorganisms (Aeromonas, Vibrio cholera, Mycobacterium avium). Because no published data exist concerning the physicochemical environment in C. elegans intestine ( $\mathrm{pH}$, oxygen level), the feasibility of anaerobic bacteria studies on C. elegans must be investigated.

A collection of human pathogens has been studied using $C$. elegans model (Table 2). Future opportunities could be to enlarge the panel of pathogens studied. The study of Hwang et al. (174) demonstrated that $C$. elegans is an effective model to examine and compare the pathogenicity and virulence variation of STEC strains (24 strains tested) to that of E. coli OP50 strain. White and
Herman (80) demonstrated the merit of a C. elegans approach in the identification of novel genes that are involved in combating the emerging nosocomial bacterial pathogen Stenotrophomonas maltophilia infection. The work of Wan et al. (175) provides new insights into the pathogenesis of $B$. thuringiensis, and highlights the importance of breaking down host epithelial junctions for a successful infection. A similar mechanism could be used by other pathogen-host interactions since epithelial junctions are conserved structures from insects to mammals. Efforts have to be made to further elucidate the evolutionary conserved mechanisms of bacterial and fungal pathogenesis as well as of host-microbes interactions. A lethal impact of microbiota of inflamed colon from inflammatory bowel disease (IBD) patient's toxicity in C. elegans compared with microbiota from the non-inflamed site of the colon was reported. Moreover, in these conditions, the co-exposure of human pathogen Giardia duodenalis increased lethal toxicity (176). Another study showed that co-infection of C. elegans with two human pathogens such as C. albicans and E. faecalis, had less severe toxic impact than either pathogen alone. The authors hypothesized that this observed effect was due to inhibition of $C$. albicans induced hyphal morphogenesis by E. faecalis derived antifungal compounds (177). This worm model offers the opportunity to explore potential trans-kingdom interactions, to define the function of

TABLE 2 | Pathogen-LAB interactions studied in the C. elegans intestine.

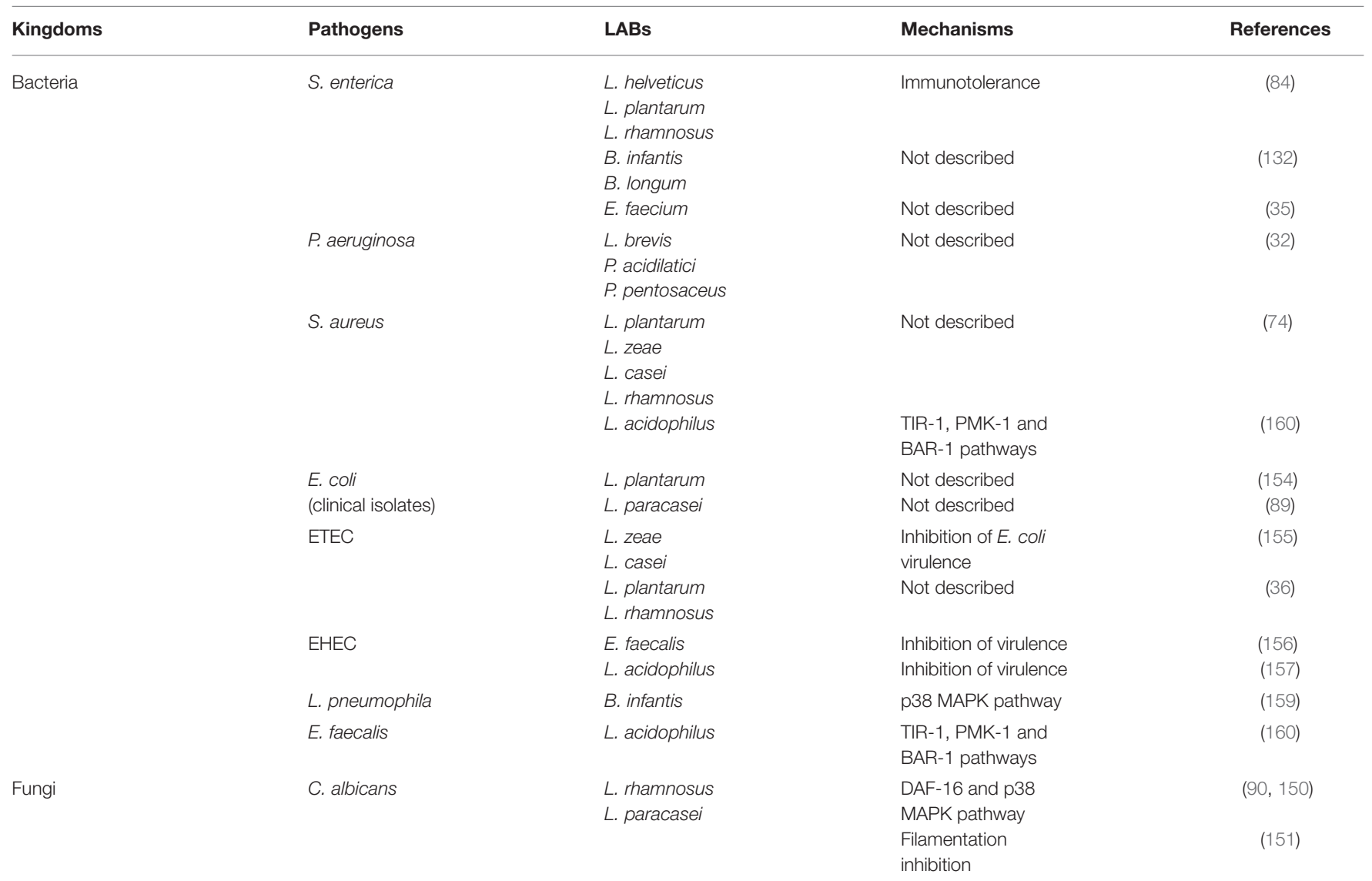


the commensal microbiota and the host-microbiota-pathogens interactions. The next challenge is to use C. elegans to study multi-infections to define the relationships and the influences of microbes on each other. In the coming years, this in vivo model could be widely used to better characterize microorganisms using omics approaches associated with automation. Although being one of the most common procedures required during C. elegans research, counting nematode numbers is a timeconsuming and fastidious process, and prone to errors. A new estimation procedure needs to be developed to make faster and reliable data collection from a worm population. A technical progress through automation would allow to enlarge applications to the screening of large microorganisms collections (178, 179). Microfluidic represents new perspectives to manipulate C. elegans in a high-throughput fashion to perform automated studies using high-resolution imaging methods (180). There is an urgent need for the discovery of effective new antimicrobial agents to combat the rise of bacterial drug resistance. Highthroughput screening (HTS) in whole-animal infection models could represent a powerful tool for identifying compounds that show antibacterial activity and low host toxicity (181-183). Research works are focused on LAB and their anti-pathogen activities, their capacities to extend lifespan of C. elegans and to manage with oxidative stress and inflammation, but some domain of research in relation with human health and nutrition have not been exploited yet.

According to its natural complex living environment, it is likely that the wild C. elegans intestine is colonized with many different microorganisms. With the aim to be ever closer to the human intestine, one of the future challenges will be to deal with a diversified worm fed, to manage colonization of $C$. elegans intestine with a consortium of strains (184). It would be of interest to enlarge the panel of experiments with C. elegans, feeding it with a complex microbiota (intestinal, vaginal, buccal, etc.) or with fermented food (raw milk cheese) to evaluate the impact of these microorganisms mixes on its lifespan, to observe

\section{REFERENCES}

1. FAO/WHO. Evaluation of health and nutritional properties of probiotics in food including powder milk with live acid bacteria. Report of a Joint FAO/WHO Expert Consultation, Córdoba, Argentina (2001). Available online at: http://www.who.int/foodsafety/publications/fs_management/en/ probiotics.pdf?ua $=1$

2. Olle B. Medicines from microbiota. Nat Biotechnol. (2013) 31:30915. doi: $10.1038 /$ nbt.2548

3. Desreumaux P, Pavan S, Mercenier A. Probiotiques, prébiotiques et symbiotiques. La Lett Hépato Gastroentérol. (2000) 3:335-7.

4. Plaza-Diaz J, Ruiz-Ojeda FJ, Gil-Campos M, Gil A. Mechanisms of action of probiotics. Adv Nutr. 10(Suppl. 1):S49-66. doi: 10.1093/advances/nmy063

5. Shokryazdan P, Jahromi MF, Liang JB, Ramasamy K, Sieo CC, Ho YW. Effects of a Lactobacillus salivarius mixture on performance, intestinal health and serum lipids of broiler chickens. PLOS ONE. (2017) 12:e0175959. doi: 10.1371/journal.pone.0175959

6. Papadimitriou K, Zoumpopoulou G, Foligné B, Alexandraki V, Kazou $\mathrm{M}$, Pot $\mathrm{B}$, et al. Discovering probiotic microorganisms: In vitro, in vivo, genetic and omics approaches. Front Microbiol. (2015) 6:58. doi: $10.3389 /$ fmicb.2015.00058 the transit of the microorganisms through the intestine and then their potential to colonize it. The feasibility of using this model to generate human-like microbiota in the worm intestine has never been reported but represents a scientific challenge for large scales studies focusing on host-microbiota or host-holobiont.

\section{CONCLUSION}

The literature mainly highlights the probiotic impact of LAB strains exerting highly beneficial effects on C. elegans whether it be on biotic and abiotic stresses or on immunity. The fact that the worm presents genetic, functional, and physiological similarities with humans represents a plus value to in vitro cellculture strategies to investigate molecular probiotic mechanisms. The C. elegans model provides a large range of opportunities to explore trans-kingdom interactions and to solve questioning about the molecular aspect of these interactions. It represents a pertinent, easy-to-handle, cheap and rapid tool for the screening of microorganisms' collections looking for specific probiotic characters. C. elegans should emerge as one of the most powerful, bioethical, and pertinent go-between model host between in vitro and mammalian models.

\section{AUTHOR CONTRIBUTIONS}

$\mathrm{CP}, \mathrm{CC}$, and SB writing-original draft. AN and SB supervision. All authors contributed to the article and approved the submitted version.

\section{FUNDING}

This work was supported by the European funds FEDER and the Auvergne-Rhône-Alpes Region in the form of grants to $\mathrm{CP}$ as well as biose ${ }^{\circledR}$ as part of the doctoral thesis of CP. The funder biose ${ }^{\circledR}$ provided support in the form of salaries for AN.
7. Douglas AE. Which experimental systems should we use for human microbiome science? PLoS Biol. (2018) 16:e2005245. doi: 10.1371/journal.pbio.2005245

8. Zannad F, Pletan Y. Difficultés à la réalisation des essais cliniques en France. Giens: Rencontres Nationales de Pharmacologie Clinique (2000)

9. Lacroix C, de Wouters T, Chassard C. Integrated multi-scale strategies to investigate nutritional compounds and their effect on the gut microbiota. Curr Opin Biotechnol. (2015) 32:149-55. doi: 10.1016/j.copbio.2014.12.009

10. Richmond J. Refinement, reduction, and replacement of animal use for regulatory testing: future improvements and implementation within the regulatory framework. ILAR J. (2002) 43:S63-68. doi: 10.1093/ilar.43.Suppl_1.S63

11. Grompone G, Martorell P, Llopis S, González N, Genovés S, Mulet AP, et al. Anti-inflammatory Lactobacillus rhamnosus CNCM I-3690 strain protects against oxidative stress and increases lifespan in Caenorhabditis elegans. PLoS ONE. (2012) 7:e52493. doi: 10.1371/journal.pone.0052493

12. Gammon DB. Caenorhabditis elegans as an emerging model for virus-host interactions. J Virol. (2017) 91:e00509-17. doi: 10.1128/JVI.00509-17

13. Issi L, Rioux M, Rao R. The nematode Caenorhabditis Elegans - a versatile in vivo model to study host-microbe interactions. J Vis Exp. (2017) 128:56487. doi: $10.3791 / 56487$ 
14. Kumar A, Baruah A, Tomioka M, Iino Y, Kalita MC, Khan M. Caenorhabditis elegans: a model to understand host-microbe interactions. Cell Mol Life Sci. (2019) 77:1229-49. doi: 10.1007/s00018-019-03319-7

15. Riddle DL, Blumenthal T, Meyer BJ, Priess JR. Section II origins of the model. In: C. elegans II. New York, NY: Cold Spring Harbor Laboratory Press. (2017). p. 1948-50. Available online at: https://www.ncbi.nlm.nih.gov/ books/NBK20127/ (accessed February 9, 2017)

16. Brenner S. The genetics of behaviour. Br Med Bull. (1973) 29:26971. doi: 10.1093/oxfordjournals.bmb.a071019

17. Brenner S. The nematode Caenorhabditis Elegans. Cold Spring, NY: Harbor Laboratory Press. (1988).

18. Ewbank JJ. Tackling both sides of the host - pathogen equation with Caenorhabditis elegans. Microbes Infect. (2002) 4:247-56. doi: 10.1016/S1286-4579(01)01531-3

19. Dong X, Liu OW, Howell AS, Shen K. An extracellular adhesion molecule complex patterns dendritic branching and morphogenesis. Cell. (2013) 155:296-307. doi: 10.1016/j.cell.2013.08.059

20. Couillault C, Kurz CL. Du nématode Caenorhabditis elegans et de son utilisation en laboratoire. Stal. (2010) 36:59-74.

21. McGhee J. The C. elegans intestine. WormBook. (2007) 1-36. doi: 10.1895/wormbook.1.133.1

22. Balla KM, Troemel ER. Caenorhabditis elegans as a model for intracellular pathogen infection. Cell Microbiol. (2013) 15:1313-22. doi: $10.1111 / \mathrm{cmi} .12152$

23. The C. elegans sequencing consortium. Genome sequence of the nematode C. elegans: a platform for investigating biology. Science. (1998) 282:201218. doi: $10.1126 /$ science.282.5396.2012

24. Lai CH, Chou CY, Ch'ang LY, Liu CS, Lin W. Identification of novel human genes evolutionarily conserved in Caenorhabditis elegans by comparative proteomics. Genome Res. (2000) 10:703-13. doi: 10.1101/gr.10.5.703

25. Wormbase. daf-2 (gene). (2011) Available online at: http://www.wormbase. org/species/c_elegans/gene/WBGene00000898\#0-9g-3 (accessed February $15,2017)$

26. Wormbase. daf-16 (gene). (2015) Available online at: http://www.wormbase. org/species/c_elegans/gene/WBGene00000912\#0e-9g-3 (accessed February 15, 2017)

27. Sun L, Zhi L, Shakoor S, Liao K, Wang D. microRNAs involved in the control of innate immunity in Candida infected Caenorhabditis elegans. Sci Rep. (2016) 6:36036. doi: 10.1038/srep36036

28. Marudhupandiyan S, Balamurugan K. Intrinsic JNK-MAPK pathway involvement requires daf-16-mediated immune response during Shigella flexneri infection in C. elegans. Immunol Res. (2017) 65:609-21. doi: 10.1007/s12026-016-8879-6

29. Zhou M, Liu X, Yu H, Yin X, Nie S-P, Xie M-Y, et al. Cell signaling of Caenorhabditis elegans in response to enterotoxigenic Escherichia coli infection and Lactobacillus zeae protection. Front Immunol. (2018) 9:1745. doi: 10.3389/fimmu.2018.01745

30. Tan MW, Rahme LG, Sternberg JA, Tompkins RG, Ausubel FM. Pseudomonas aeruginosa killing of Caenorhabditis elegans used to identify P. aeruginosa virulence factors. Proc Natl Acad Sci USA. (1999) 96:240813. doi: $10.1073 /$ pnas.96.5.2408

31. Tan MW, Mahajan-Miklos S, Ausubel FM. Killing of Caenorhabditis elegans by Pseudomonas aeruginosa used to model mammalian bacterial pathogenesis. Proc Natl Acad Sci USA. (1999) 96:71520. doi: 10.1073/pnas.96.2.715

32. Chelliah R, Choi J-G, Hwang S-B, Park B-J, Daliri EB-M, Kim S-H, et al. In vitro and in vivo defensive effect of probiotic LAB against Pseudomonas aeruginosa using Caenorhabditis elegans model. Virulence. (2018) 9:1489507. doi: 10.1080/21505594.2018.1518088

33. Garsin DA, Sifri CD, Mylonakis E, Qin X, Singh KV, Murray BE, et al. A simple model host for identifying gram-positive virulence factors. Proc Natl Acad Sci USA. (2001) 98:10892-7. doi: 10.1073/pnas.191378698

34. Park MR, Ryu S, Maburutse BE, Oh NS, Kim SH, Oh S, et al. Probiotic Lactobacillus fermentum strain JDFM216 stimulates the longevity and immune response of Caenorhabditis elegans through a nuclear hormone receptor. Sci Rep. (2018) 8:7441. doi: 10.1038/s41598-018-25333-8

35. Sim I, Park KT, Kwon G, Koh JH, Lim YH. Probiotic potential of Enterococcus faecium isolated from chicken cecum with immunomodulating activity and promoting longevity in Caenorhabditis elegans. J Microbiol Biotechnol. (2018) 28:883-92. doi: 10.4014/jmb.1802.02019

36. Heo J, Shin D, Chang SY, Bogere P, Park MR, Ryu S, et al. Comparative genome analysis and evaluation of probiotic characteristics of Lactobacillus plantarum strain JDFM LP11. Korean J Food Sci Anim Resour. (2018) 38:878-88. doi: 10.5851/kosfa.2018.e21

37. Kamaladevi A, Balamurugan K. Lactobacillus casei triggers a TLR mediated RACK-1 dependent p38 MAPK pathway in Caenorhabditis elegans to resist Klebsiella pneumoniae infection. Food Funct. (2016) 7:321123. doi: 10.1039/C6FO00510A

38. Rijkers GT, Bengmark S, Enck P, Haller D, Herz U, Kalliomaki M, et al. Guidance for substantiating the evidence for beneficial effects of probiotics: current status and recommendations for future research. J Nutr. (2010) 140:671S-6S. doi: 10.3945/jn.109.113779

39. Nathan S. New to Galleria mellonella: modeling an ExPEC infection. Virulence. (2014) 5:371-4. doi: 10.4161/viru.28338

40. Swanson PA, Kumar A, Samarin S, Vijay-Kumar M, Kundu K, Murthy N, et al. Enteric commensal bacteria potentiate epithelial restitution via reactive oxygen species-mediated inactivation of focal adhesion kinase phosphatases. Proc Natl Acad Sci USA. (2011) 108:8803-8. doi: 10.1073/pnas.1010042108

41. Hooper LV, Littman DR, Macpherson AJ. Interactions between the microbiota and the immune system. Science. (2012) 336:1268-73. doi: 10.1126/science. 1223490

42. Spor A, Koren O, Ley R. Unravelling the effects of the environment and host genotype on the gut microbiome. Nat Rev Microbiol. (2011) 9:27990. doi: $10.1038 /$ nrmicro2540

43. Kostic AD, Howitt MR, Garrett WS. Exploring host-microbiota interactions in animal models and humans. Genes Dev. (2013) 27:701-18. doi: 10.1101/gad.212522.112

44. Chung H, Pamp SJ, Hill JA, Surana NK, Edelman SM, Troy EB, et al. Gut immune maturation depends on colonization with a host-specific microbiota. Cell. (2012) 149:1578-93. doi: 10.1016/j.cell.2012.04.037

45. Arrieta M-C, Walter J, Finlay BB. Human microbiota-associated mice: a model with challenges. Cell Host Microbe. (2016) 19:575-8. doi: 10.1016/j.chom.2016.04.014

46. Hardin-Pouzet H, Morosan S. Des souris, des rats et des hommes. Méd Sci. (2019) 35:479-82. doi: 10.1051/medsci/2019082

47. Lee JG, Sung YH, Baek I-J. Generation of genetically-engineered animals using engineered endonucleases. Arch Pharm Res. (2018) 41:885-97. doi: 10.1007/s12272-018-1037-z

48. Li M, Lee K, Hsu M, Nau G, Mylonakis E, Ramratnam B. Lactobacillusderived extracellular vesicles enhance host immune responses against vancomycin-resistant enterococci. BMC Microbiol. (2017) 17:66. doi: 10.1186/s12866-017-0977-7

49. Duncker SC, Kamiya T, Wang L, Yang P, Bienenstock J. Probiotic Lactobacillus reuteri alleviates the response to gastric distension in rats. $J$ Nutr. (2011) 141:1813-18. doi: 10.3945/jn.110.136689

50. Plaza-Díaz J, Robles-Sánchez C, Abadía-Molina F, Sáez-Lara MJ, VilchezPadial LM, Gil Á, et al. Gene expression profiling in the intestinal mucosa of obese rats administered probiotic bacteria. Sci Data. (2017) 4:170186. doi: $10.1038 /$ sdata.2017.186

51. Fukui H, Oshima T, Tanaka Y, Oikawa Y, Makizaki Y, Ohno H, et al. Effect of probiotic Bifidobacterium bifidum G9-1 on the relationship between gut microbiota profile and stress sensitivity in maternally separated rats. Sci Rep. (2018) 8:12384. doi: 10.1038/s41598-018-30943-3

52. Mazloom K, Siddiqi I, Covasa M. Probiotics: how effective are they in the fight against obesity? Nutrients. (2019) 11:258. doi: 10.3390/nu11020258

53. Tong C, Li P, Wu NL, Yan Y, Ying Q-L. Production of p53 gene knockout rats by homologous recombination in embryonic stem cells. Nature. (2010) 467:211-13. doi: 10.1038/nature09368

54. Li D, Qiu Z, Shao Y, Chen Y, Guan Y, Liu M, et al. Heritable gene targeting in the mouse and rat using a CRISPR-Cas system. Nat Biotechnol. (2013) 31:681-3. doi: $10.1038 /$ nbt.2661

55. Ericsson AC. The use of non-rodent model species in microbiota studies. Lab Anim. (2019) 53:259-70. doi: 10.1177/0023677219834593

56. Rawls JF, Mahowald MA, Ley RE, Gordon JI. Reciprocal gut microbiota transplants from zebrafish and mice to germ-free recipients reveal host habitat selection. Cell. (2006) 127:423-33. doi: 10.1016/j.cell.2006.08.043 
57. Roeselers G, Mittge EK, Stephens WZ, Parichy DM, Cavanaugh CM, Guillemin $\mathrm{K}$, et al. Evidence for a core gut microbiota in the zebrafish. ISME J. (2011) 5:1595-608. doi: 10.1038/ismej.2011.38

58. Russell WM., Burch RL. The Principles of Humane Experimental Technique. Wheathampstead; London: Universities Federation for Animal Welfare (1959). Available online at: http://altweb.jhsph.edu/pubs/books/humane_ exp/het-toc (accessed July 18, 2019)

59. Richmond J. The 3Rs - past, present and future. Scand J Lab Anim Sci. (2000) 27:84-92. doi: 10.23675/sjlas.v27i2.19

60. Lemaitre B, Hoffmann J. The host defense of Drosophila melanogaster. Annu Rev Immunol. (2007) 25:69743. doi: 10.1146/annurev.immunol.25.022106.141615

61. Apidianakis Y, Rahme LG. Drosophila melanogaster as a model for human intestinal infection and pathology. Dis Model Mech. (2011) 4:2130. doi: 10.1242/dmm.003970

62. Koyle ML, Veloz M, Judd AM, Wong AC-N, Newell PD, Douglas AE, et al. Rearing the fruit fly Drosophila melanogaster under axenic and gnotobiotic conditions. J Vis Exp. (2016) 113:54219. doi: 10.3791/54219

63. Blum JE, Fischer CN, Miles J, Handelsman J. Frequent replenishment sustains the beneficial microbiome of Drosophila melanogaster. MBio. (2013) 4:e00860-13. doi: 10.1128/mBio.00860-13

64. Erkosar B, Storelli G, Defaye A, Leulier F. Host-intestinal microbiota mutualism: "Learning on the Fly." Cell Host Microbe. (2013) 13:814. doi: 10.1016/j.chom.2012.12.004

65. Chaston JM, Newell PD, Douglas AE. Metagenome-wide association of microbial determinants of host phenotype in Drosophila melanogaster. MBio. (2014) 5:e01631-14. doi: 10.1128/mBio.01631-14

66. Trinder M, Daisley BA, Dube JS, Reid G. Drosophila melanogaster as a highthroughput model for host-microbiota interactions. Front Microbiol. (2017) 8:751. doi: 10.3389/fmicb.2017.00751

67. Gómez E, Martín F, Nogacka AM, Salazar N, Aláez L, Alcorta E, et al. Impact of probiotics on development and behaviour in Drosophila melanogaster - a potential in vivo model to assess probiotics. Benef Microbes. (2019) 10:179-88. doi: 10.3920/BM2018.0012

68. Ramarao N, Nielsen-Leroux C, Lereclus D. The insect Galleria mellonella as a powerful infection model to investigate bacterial pathogenesis. J Vis Exp. (2012) 70:e4392. doi: 10.3791/4392

69. Mukherjee K, Raju R, Fischer R, Vilcinskas A. Galleria Mellonella as a model host to study gut microbe homeostasis and brain infection by the human pathogen Listeria Monocytogenes. In: Vilcinskas A, editor. Advances in Biochemical Engineering/Biotechnology, Vol. 135. Berlin; Heidelberg: Springer (2013). p. 27-39. doi: 10.1007/10_2013_203

70. Fuchs BB, O’Brien E, El Khoury JB, Mylonakis E. Methods for using Galleria mellonella as a model host to study fungal pathogenesis. Virulence. (2010) 1:475-82. doi: 10.4161/viru.1.6.12985

71. Fallon J, Kelly J, Kavanagh K. Galleria mellonella as a model for fungal pathogenicity testing. In: Brand A, MacCallum D, editors. Host-Fungus Interactions. Methods in Molecular Biology (Methods and Protocols), Vol. 845. Humana Press (2012). doi: 10.1007/978-1-61779-539-8_33

72. Vilela SF, Barbosa JO, Rossoni RD, Santos JD, Prata MC, Anbinder AL, et al. Lactobacillus acidophilus ATCC 4356 inhibits biofilm formation by C. albicans and attenuates the experimental candidiasis in galleria mellonella. Virulence. (2015) 6:29-39. doi: 10.4161/21505594.2014.981486

73. Jiang H, Wang D. The microbial zoo in the C. elegans intestine: bacteria, fungi and viruses. Viruses. (2018) 10:85. doi: 10.3390/v10020085

74. Park MR, Yun HS, Son SJ, Oh S, Kim Y. Short communication: development of a direct in vivo screening model to identify potential probiotic bacteria using Caenorhabditis elegans. J Dairy Sci. (2014) 97:682834. doi: 10.3168/jds.2014-8561

75. Lee HK, Choi S-H, Lee CR, Lee SH, Park MR, Kim Y, et al. Screening and characterization of lactic acid bacteria strains with anti-inflammatory activities through in vitro and Caenorhabditis elegans model testing. Korean J Food Sci Anim Resour. (2015) 35:91-100. doi: 10.5851/kosfa.2015.35.1.91

76. Schifano E, Zinno P, Guantario B, Roselli M, Marcoccia S, Devirgiliis C, et al. The foodborne strain Lactobacillus fermentum MBC2 triggers pept-1dependent pro-longevity effects in Caenorhabditis elegans. Microorganisms. (2019) 7:45. doi: 10.3390/microorganisms7020045
77. Chalfie M, Tu Y, Euskirchen G, Ward W, Prasher D. Green fluorescent protein as a marker for gene expression. Science. (1994) 263:8025. doi: 10.1126/science.8303295

78. Jeon H, Cha DS. Anti-aging properties of Ribes fasciculatum in Caenorhabditis elegans. Chin J Nat Med. (2016) 14:33542. doi: 10.3724/SP.J.1009.2016.00335

79. Cassidy L, Petersen C, Treitz C, Dierking K, Schulenburg H, Leippe M, et al. The Caenorhabditis elegans proteome response to naturally associated microbiome members of the genus Ochrobactrum. Proteomics. (2018) 18:1700426. doi: 10.1002/pmic.201700426

80. White CV, Herman MA. Transcriptomic, functional, and network analyses reveal novel genes involved in the interaction between Caenorhabditis elegans and Stenotrophomonas maltophilia. Front Cell Infect Microbiol. (2018) 8:266. doi: $10.3389 /$ fcimb.2018.00266

81. Sharika R, Subbaiah P, Balamurugan K. Studies on reproductive stress caused by candidate gram positive and gram negative bacteria using model organism, Caenorhabditis elegans. Gene. (2018) 649:113-26. doi: 10.1016/j.gene.2018.01.088

82. Yang W, Dierking K, Esser D, Tholey A, Leippe M, Rosenstiel P, et al. Overlapping and unique signatures in the proteomic and transcriptomic responses of the nematode Caenorhabditis elegans toward pathogenic Bacillus thuringiensis. Dev Comp Immunol. (2015) 51:1-9. doi: 10.1016/j.dci.2015.02.010

83. Park H-EH, Jung Y, Lee S-J V. Survival assays using Caenorhabditis elegans. Mol Cells. (2017) 40:90-99. doi: 10.14348/molcells.2017.0017

84. Ikeda T, Yasui C, Hoshino K, Arikawa K, Nishikawa Y. Influence of lactic acid bacteria on longevity of Caenorhabditis elegans and host defense against Salmonella enterica serovar enteritidis. Appl Environ Microbiol. (2007) 73:6404-9. doi: 10.1128/AEM.00704-07

85. Lenaerts I, Walker GA, Van Hoorebeke L, Gems D, Vanfleteren JR. Dietary restriction of Caenorhabditis elegans by axenic culture reflects nutritional requirement for constituents provided by metabolically active microbes. $J$ Gerontol A Biol Sci Med Sci. (2008) 63:242-52. doi: 10.1093/gerona/63.3.242

86. Nakagawa H, Shiozaki T, Kobatake E, Hosoya T, Moriya T, Sakai F, et al. Effects and mechanisms of prolongevity induced by Lactobacillus gasseri SBT2055 in Caenorhabditis elegans. Aging Cell. (2016) 15:22736. doi: 10.1111/acel.12431

87. Kato M, Hamazaki Y, Sun S, Nishikawa Y, Kage-Nakadai E. Clostridium butyricum MIYAIRI 588 increases the lifespan and multiple-stress resistance of Caenorhabditis elegans. Nutrients. (2018) 10:1921. doi: 10.3390/nu10121921

88. Kwon G, Lee J, Lim Y-H. Dairy Propionibacterium extends the mean lifespan of Caenorhabditis elegans via activation of the innate immune system. Sci Rep. (2016) 6:31713. doi: 10.1038/srep31713

89. Sharma K, Pooranachithra M, Balamurugan K, Goel G. Probiotic mediated colonization resistance against E.coli infection in experimentally challenged Caenorhabditis elegans. Microb Pathog. (2019) 127:39-47. doi: 10.1016/j.micpath.2018.11.041

90. Poupet C, Saraoui T, Veisseire P, Bonnet M, Dausset C, Gachinat $\mathrm{M}$, et al. Lactobacillus rhamnosus Lcr35 as an effective treatment for preventing Candida albicans infection in the invertebrate model Caenorhabditis elegans: first mechanistic insights. PLoS ONE. (2019) 14:e0216184. doi: 10.1371/journal.pone.0216184

91. Wang S, Ahmadi S, Nagpal R, Jain S, Mishra SP, Kavanagh K, et al. Lipoteichoic acid from the cell wall of a heat killed Lactobacillus paracasei D3-5 ameliorates aging-related leaky gut, inflammation and improves physical and cognitive functions: from C. elegans to mice. Geroscience. (2019) 42:333-52. doi: 10.1007/s11357-019-00137-4

92. Fasseas MK, Fasseas C, Mountzouris KC, Syntichaki P. Effects of Lactobacillus salivarius, Lactobacillus reuteri, and Pediococcus acidilactici on the nematode Caenorhabditis elegans include possible antitumor activity. Appl Microbiol Biotechnol. (2013) 97:2109-18. doi: 10.1007/s00253-012-4357-9

93. Komura T, Ikeda T, Yasui C, Saeki S, Nishikawa Y. Mechanism underlying prolongevity induced by bifidobacteria in Caenorhabditis elegans. Biogerontology. (2013) 14:73-87. doi: 10.1007/s10522-0129411-6 
94. Zhao L, Zhao Y, Liu R, Zheng X, Zhang M, Guo $H$, et al. The transcription factor DAF-16 is essential for increased longevity in C. elegans exposed to bifidobacterium longum BB68. Sci Rep. (2017) 7:7408. doi: 10.1038/s41598-017-07974-3

95. Mooijaart SP, Brandt BW, Baldal EA, Pijpe J, Kuningas M, Beekman $\mathrm{M}$, et al. C. elegans DAF-12, nuclear hormone receptors and human longevity and disease at old age. Ageing Res Rev. (2005) 4:35171. doi: 10.1016/j.arr.2005.03.006

96. Sun S, Mizuno Y, Komura T, Nishikawa Y, Kage-Nakadai E. Toll-like receptor homolog TOL-1 regulates Bifidobacterium infantis-elicited longevity and behavior in Caenorhabditis elegans. Biosci Microbiota Food Heal. (2019) 38:105-10. doi: 10.12938/bmfh.18-031

97. Halaschek-Wiener J, Khattra JS, McKay S, Pouzyrev A, Stott JM, Yang GS, et al. Analysis of long-lived C. elegans daf-2 mutants using serial analysis of gene expression. Genome Res. (2005) 15:603-15. doi: 10.1101/gr.3274805

98. Hsu A-L. Regulation of aging and age-related disease by DAF-16 and heatshock factor. Science. (2003) 300:1142-45. doi: 10.1126/science.1083701

99. Sugawara T, Sakamoto K. Killed Bifidobacterium longum enhanced stress tolerance and prolonged life span of Caenorhabditis elegans via DAF-16. Br J Nutr. (2018) 120:872-80. doi: 10.1017/S0007114518001563

100. Francis R, Barton MK, Kimble J, Schedl T. gld-1, a tumor suppressor gene required for oocyte development in Caenorhabditis elegans. Genetics. (1995) 139:579-606.

101. Zhong L, Zhang X, Covasa M. Emerging roles of lactic acid bacteria in protection against colorectal cancer. World J Gastroenterol. (2014) 20:7878. doi: 10.3748/wjg.v20.i24.7878

102. Tarrah A, De Castilhos J, Rossi RC, Da Silva Duarte V, Ziegler DR, Corich $\mathrm{V}$, et al. In vitro probiotic potential and anti-cancer activity of newly isolated folate-producing streptococcus thermophilus strains. Front Microbiol. (2018) 9:2214. doi: 10.3389/fmicb.2018.02214

103. Kwon G, Lee J, Koh J-H, Lim Y-H. Lifespan extension of Caenorhabditis elegans by Butyricicoccus pullicaecorum and Megasphaera elsdenii with probiotic potential. Curr Microbiol. (2018) 75:557-64. doi: 10.1007/s00284-017-1416-6

104. Veisseire P, Bonnet M, Saraoui T, Poupet C, Camar O, Gachinat $\mathrm{M}$, et al. Investigation into in vitro and in vivo Caenorhabditis elegans models to select cheese yeasts as probiotic candidates for their preventive effects against Salmonella Typhimurium. Microorganisms. (2020) 8:922. doi: $10.3390 /$ microorganisms 8060922

105. Fontana L, Partridge L, Longo VD. Extending healthy life span-from yeast to humans. Science. (2010) 328:321-6. doi: 10.1126/science.1172539

106. Kenyon CJ. The genetics of ageing. Nature. (2010) 464:50412. doi: $10.1038 /$ nature 08980

107. Ewald CY, Castillo-Quan JI, Blackwell TK. Untangling longevity, dauer, and healthspan in Caenorhabditis elegans insulin/IGF-1-signalling. Gerontology. (2018) 64:96-104. doi: 10.1159/000480504

108. Murphy CT, Hu PJ. Insulin/insulin-life growth factor signaling in C. elegans. WormBook. (2013) 1-30. doi: 10.1895/wormbook.1.164.1

109. Xu A, Shi G, Liu F, Ge B. Caenorhabditis elegans mom-4 is required for the activation of the p38 MAPK signaling pathway in the response to Pseudomonas aeruginosa infection. Protein Cell. (2013) 4:53-61. doi: 10.1007/s13238-012-2080-z

110. Troemel ER, Chu SW, Reinke V, Lee SS, Ausubel FM, Kim DH. p38 MAPK regulates expression of immune response genes and contributes to longevity in C. elegans. PLoS Genet. (2006) 2:1725-39. doi: 10.1371/journal.pgen.0020183

111. Neumann-Haefelin E, Qi W, Finkbeiner E, Walz G, Baumeister R, Hertweck M. SHC-1/p52Shc targets the insulin/IGF-1 and JNK signaling pathways to modulate life span and stress response in C. elegans. Genes Dev. (2008) 22:2721-35. doi: 10.1101/gad.478408

112. Wolf M, Nunes F, Henkel A, Heinick A, Paul RJ. The MAP kinase JNK-1 of Caenorhabditis elegans: location, activation, and influences over temperature-dependent insulin-like signaling, stress responses, and fitness. J Cell Physiol. (2008) 214:721-9. doi: 10.1002/jcp.21269

113. Oh SW, Mukhopadhyay A, Svrzikapa N, Jiang F, Davis RJ, Tissenbaum HA. JNK regulates lifespan in Caenorhabditis elegans by modulating nuclear translocation of forkhead transcription factor/DAF-16. Proc Natl Acad Sci USA. (2005) 102:4494-9. doi: 10.1073/pnas.0500749102
114. Donato V, Ayala FR, Cogliati S, Bauman C, Costa JG, Leñini C, et al. Bacillus subtilis biofilm extends Caenorhabditis elegans longevity through downregulation of the insulin-like signalling pathway. Nat Commun. (2017) 8:14332. doi: $10.1038 /$ ncomms 14332

115. Gusarov I, Gautier L, Smolentseva O, Shamovsky I, Eremina S, Mironov A, et al. Bacterial nitric oxide extends the lifespan of C. elegans. Cell. (2013) 152:818-30. doi: 10.1016/j.cell.2012.12.043

116. Clark LC, Hodgkin J. Commensals, probiotics and pathogens in the Caenorhabditis elegans model. Cell Microbiol. (2014) 16:27-38. doi: 10.1111/cmi.12234

117. Rasamiravaka T, Vandeputte OM, Pottier L, Huet J, Rabemanantsoa C, Kiendrebeogo M, et al. Pseudomonas aeruginosa biofilm formation and persistence, along with the production of quorum sensing-dependent virulence factors, are disrupted by a triterpenoid coumarate ester isolated from Dalbergia trichocarpa, a tropical legume. PLoS ONE. (2015) 10:e132791. doi: 10.1371/journal.pone.0132791

118. Oh S, Go GW, Mylonakis E, Kim Y. The bacterial signalling molecule indole attenuates the virulence of the fungal pathogen Candida albicans. J Appl Microbiol. (2012) 113:622-8. doi: 10.1111/j.1365-2672.2012.05372.x

119. Williams P. Quorum sensing, communication and crosskingdom signalling in the bacterial world. Microbiology. (2007) 153:3923-38. doi: 10.1099/mic.0.2007/012856-0

120. Fujiya M, Musch MW, Nakagawa Y, Hu S, Alverdy J, Kohgo Y, et al. The Bacillus subtilis quorum-sensing molecule CSF contributes to intestinal homeostasis via OCTN2, a host cell membrane transporter. Cell Host Microbe. (2007) 1:299-308. doi: 10.1016/j.chom.2007.05.004

121. Harman D. Aging: a theory based on free radical and radiation chemistry. $J$ Gerontol. (1956) 11:298-300. doi: 10.1093/geronj/11.3.298

122. Valko M, Leibfritz D, Moncol J, Cronin MTD, Mazur M, Telser J. Free radicals and antioxidants in normal physiological functions and human disease. Int J Biochem Cell Biol. (2007) 39:44-84. doi: 10.1016/j.biocel.2006.07.001

123. Labuschagne CF, Stigter ECA, Hendriks MMWB, Berger R, Rokach $\mathrm{J}$, Korswagen $\mathrm{HC}$, et al. Quantification of in vivo oxidative damage in Caenorhabditis elegans during aging by endogenous F3-isoprostane measurement. Aging Cell. (2013) 12:214-23. doi: 10.1111/acel.12043

124. Ristow M, Schmeisser S. Extending life span by increasing oxidative stress. Free Radic Biol Med. (2011) 51:32736. doi: 10.1016/j.freeradbiomed.2011.05.010

125. Southam CM, Ehrlich J. Effects of exact of western red-dedar heartwood on certain wood-decaying fungi in culture. Phytopathology. (1943) 33:517-24.

126. Cypser JR, Tedesco P, Johnson TE. Hormesis and aging in Caenorhabditis elegans. Exp Gerontol. (2006) 41:935-9. doi: 10.1016/j.exger.2006.09.004

127. Sasakura H, Moribe H, Nakano M, Ikemoto K, Takeuchi K, Mori I. Lifespan extension by peroxidase and dual oxidase-mediated ROS signaling through pyrroloquinoline quinone in C. elegans. J Cell Sci. (2017) 130:263143. doi: $10.1242 /$ jcs. 202119

128. Li Y, Wei G, Chen J. Glutathione: a review on biotechnological production. Appl Microbiol Biotechnol. (2004) 66:23342. doi: 10.1007/s00253-004-1751-y

129. Kobatake E, Nakagawa H, Seki T, Miyazaki T. Protective effects and functional mechanisms of Lactobacillus gasseri SBT2055 against oxidative stress. PLoS ONE. (2017) 12:e0177106. doi: 10.1371/journal.pone.0177106

130. Clark DA, Gabel CV, Gabel H, Samuel ADT. Temporal activity patterns in thermosensory neurons of freely moving Caenorhabditis elegans encode spatial thermal gradients. J Neurosci. (2007) 27:6083-90. doi: 10.1523/JNEUROSCI.1032-07.2007

131. Prahlad V, Cornelius T, Morimoto RI. Regulation of the cellular heat shock response in Caenorhabditis elegans by thermosensory neurons. Science. (2008) 320:811-14. doi: 10.1126/science.1156093

132. Rangan KJ, Pedicord VA, Wang YC, Kim B, Lu Y, Shaham S, et al. A secreted bacterial peptidoglycan hydrolase enhances tolerance to enteric pathogens. Science. (2016) 353:1434-7. doi: 10.1126/science.aaf3552

133. Engelmann I, Pujol N. Innate immunity in C.elegans. Invertebr Immun. (2010) 708:105-19. doi: 10.1007/978-1-4419-8059-5_6

134. Kim DH. A conserved p38 MAP kinase pathway in Caenorhabditis elegans innate immunity. Science. (2002) 297:623-6. doi: 10.1126/science.10 73759 
135. Sifri CD, Begun J, Ausubel FM, Calderwood SB. Caenorhabditis elegans as a model host for Staphylococcus aureus pathogenesis. Infect Immun. (2003) 71:2208. doi: 10.1128/IAI.71.4.2208-2217.2003

136. Huffman DL, Abrami L, Sasik R, Corbeil J, van der Goot FG, Aroian R V. Mitogen-activated protein kinase pathways defend against bacterial pore-forming toxins. Proc Natl Acad Sci USA. (2004) 101:109951000. doi: 10.1073/pnas.0404073101

137. Evans EA, Chen WC, Tan MW. The DAF-2 insulin-like signaling pathway independently regulates aging and immunity in C. elegans. Aging Cell. (2008) 7:879-93. doi: 10.1111/j.1474-9726.2008.00435.x

138. Wang Y, Jian F, Wu J, Wang S. Stress-response protein expression and DAF-16 translocation were induced in tributyltin-exposed Caenorhabditis elegans. Bull Environ Contam Toxicol. (2012) 89:704-11. doi: 10.1007/s00128-012-0760-2

139. Morrison DK. MAP kinase pathways. Cold Spring Harb Perspect Biol. (2012) 4:a011254. doi: 10.1101/cshperspect.a011254

140. Pukkila-Worley R, Ausubel FM, Mylonakis E. Candida albicans infection of Caenorhabditis elegans induces antifungal immune defenses. PLoS Pathog. (2011) 7:e1002074. doi: 10.1371/journal.ppat.1002074

141. Peterson ND, Cheesman HK, Liu P, Anderson SM, Foster $\mathrm{KJ}$, Chhaya $\mathrm{R}$, et al. The nuclear hormone receptor NHR-86 controls anti-pathogen responses in C. elegans. PLoS Genet. (2019) 15:e1007935. doi: 10.1371/journal.pgen.1007935

142. Son SJ, Park MR, Ryu SD, Maburutse BE, Oh NS, Park J, et al. Short communication: in vivo screening platform for bacteriocins using Caenorhabditis elegans to control mastitis-causing pathogens. J Dairy Sci. (2016) 99:8614-21. doi: 10.3168/jds.2016-11330

143. Coolon JD, Jones KL, Todd TC, Carr BC, Herman MA. Caenorhabditis elegans genomic response to soil bacteria predicts environmentspecific genetic effects on life history traits. PLoS Genet. (2009) 5:e1000503. doi: 10.1371/journal.pgen.1000503

144. MacNeil LT, Watson E, Arda HE, Zhu LJ, Walhout AJM. Diet-induced developmental acceleration independent of TOR and insulin in C. elegans. Cell. (2013) 153:240-52. doi: 10.1016/j.cell.2013.02.049

145. Portal-Celhay C, Bradley ER, Blaser MJ. Control of intestinal bacterial proliferation in regulation of lifespan in Caenorhabditis elegans. BMC Microbiol. (2012) 12:49. doi: 10.1186/1471-2180-12-49

146. Millet ACM, Ewbank JJ. Immunity in Caenorhabditis elegans. Curr Opin Immunol. (2004) 16:4-9. doi: 10.1016/j.coi.2003.11.005

147. Kim J, Moon Y. Worm-based alternate assessment of probiotic intervention against gut barrier infection. Nutrients. (2019) 11:1-13. doi: 10.3390/nu11092146

148. Tan K, Deng D, Ma X, Cui Y, Tian Z. Pediococcus acidilactici P25 protected caenorhabditis elegans against enterotoxigenic Escherichia coli K88 infection and transcriptomic analysis of its potential mechanisms. Biomed Res Int. (2020) 2020:7340312. doi: 10.1155/2020/7340312

149. Chelliah R, Saravanakumar K, Daliri EBM, Kim JH, Lee JK, Jo H-Y, et al. Unveiling the potentials of bacteriocin (Pediocin L50) from Pediococcus acidilactici with antagonist spectrum in a Caenorhabditis elegans model. Int J Biol Macromol. (2019) 143:555-72. doi: 10.1016/j.ijbiomac.2019. 10.196

150. Poupet C, Veisseire P, Bonnet $M$, Camarès O, Gachinat $M$, Dausset $\mathrm{C}$, et al. Curative treatment of candidiasis by the live biotherapeutic

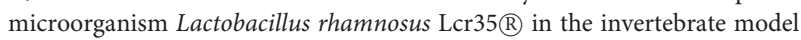
Caenorhabditis elegans: first mechanistic insights. Microorganisms. (2019) 8:34. doi: 10.3390/microorganisms 8010034

151. de Barros PP, Scorzoni L, de Ribeiro FC, de Oliveira Fugisaki LR, Fuchs $\mathrm{BB}$, Mylonakis E, et al. Lactobacillus paracasei 28.4 reduces in vitro hyphae formation of Candida albicans and prevents the filamentation in an experimental model of Caenorhabditis elegans. Microb Pathog. (2018) 117:80-87. doi: 10.1016/j.micpath.2018.02.019

152. Rousseau V. Evaluation d’oligosaccharides à effet Prébiotique vis-à-vis de la Microflore Vaginale. (2004) Available online at: http://eprint.insa-toulouse. fr/archive/00000069/ (accessed June 14, 2016)

153. Nivoliez A, Camares O, Paquet-Gachinat M, Bornes S, Forestier C, Veisseire $\mathrm{P}$. Influence of manufacturing processes on in vitro properties of the probiotic strain Lactobacillus rhamnosus Lcr35®. J Biotechnol. (2012) 160:236-41. doi: 10.1016/j.jbiotec.2012.04.005
154. Sharma K, Pooranachithra M, Balamurugan K, Goel G. Multivariate analysis of increase in life span of Caenorhabditis elegans through intestinal colonization by indigenous probiotic strains. Probiotics Antimicrob Proteins. (2018) 11:865-73. doi: 10.1007/s12602-018-9420-0

155. Zhou M, Yu H, Yin X, Sabour PM, Chen W, Gong J. Lactobacillus zeae protects Caenorhabditis elegans from enterotoxigenic Escherichia coli-caused death by inhibiting enterotoxin gene expression of the pathogen. PLoS ONE. (2014) 9:e89004. doi: 10.1371/journal.pone.0089004

156. Neuhaus K, Lamparter MC, Zölch B, Landstorfer R, Simon S, Spanier B, et al. Probiotic Enterococcus faecalis symbioflor $(\mathrm{B}$ down regulates virulence genes of EHEC in vitro and decrease pathogenicity in a Caenorhabditis elegans model. Arch Microbiol. (2017) 199:203-13. doi: 10.1007/s00203-016-1291-8

157. Kim Y, Han KS, Imm JY, Oh S, You S, Park S, et al. Inhibitory effects of Lactobacillus acidophilus lysates on the cytotoxic activity of shiga-like toxin 2 produced from Escherichia coli O157:H7. Lett Appl Microbiol. (2006) 43:502-7. doi: 10.1111/j.1472-765X.2006.02005.x

158. Chou T-C, Chiu H-C, Kuo C-J, Wu C-M, Syu W-J, Chiu W-T, et al. Enterohaemorrhagic Escherichia coli O157:H7 Shiga-like toxin 1 is required for full pathogenicity and activation of the p38 mitogen-activated protein kinase pathway in Caenorhabditis elegans. Cell Microbiol. (2013) 15:8297. doi: $10.1111 / \mathrm{cmi} .12030$

159. Komura T, Yasui C, Miyamoto H, Nishikawa Y. Caenorhabditis elegans as an alternative model host for Legionella pneumophila, and protective effects of Bifidobacterium infantis. Appl Environ Microbiol. (2010) 76:41058. doi: 10.1128/AEM.03021-09

160. Kim Y, Mylonakis E. Caenorhabditis elegans immune conditioning with the probiotic bacterium Lactobacillus acidophilus strain NCFM enhances gram-positive immune responses. Infect Immun. (2012) 80:25008. doi: 10.1128/IAI.06350-11

161. Silverman GA, Luke CJ, Bhatia SR, Long OS, Vetica AC, Perlmutter $\mathrm{DH}$, et al. Modeling molecular and cellular aspects of human disease using the nematode Caenorhabditis elegans. Pediatr Res. (2009) 65:1018. doi: 10.1203/PDR.0b013e31819009b0

162. O'Kane CJ. Modelling human diseases in Drosophila and Caenorhabditis. Semin Cell Dev Biol. (2003) 14:3-10. doi: 10.1016/S1084-9521(02)00162-3

163. Apfeld J, Alper S. What can we learn about human disease from the nematode C. elegans? Methods Mol Biol. (2018) 1706:53-75. doi: 10.1007/978-1-4939-7471-9_4

164. Ausubel FM. Are innate immune signaling pathways in plants and animals conserved? Nat Immunol. (2005) 6:973-9. doi: 10.1038/ni1253

165. Kim DH, Ausubel FM. Evolutionary perspectives on innate immunity from the study of Caenorhabditis elegans. Curr Opin Immunol. (2005) 17:410. doi: 10.1016/j.coi.2004.11.007

166. Long X, Spycher C, Han ZS, Rose AM, Müller F, Avruch J. TOR deficiency in $C$. elegans causes developmental arrest and intestinal atrophy by inhibition of mRNA translation. Curr Biol. (2002) 12:144861. doi: 10.1016/S0960-9822(02)01091-6

167. Leulier F, MacNeil LT, Lee WJ, Rawls JF, Cani PD, Schwarzer M, et al. Integrative physiology: at the crossroads of nutrition, microbiota, animal physiology, and human health. Cell Metab. (2017) 25:52234. doi: 10.1016/j.cmet.2017.02.001

168. Chen Y-W, Ko W-C, Chen C-S, Chen P-L. Evaluating virulence and pathogenesis of aeromonas infection in a Caenorhabditis elegans model. J Vis Exp. (2018) e58768. doi: 10.3791/58768

169. Rouanet A, Bolca S, Bru A, Claes I, Cvejic H, Girgis H, et al. Live biotherapeutic products, a road map for safety assessment. Front Med. (2020) 7:237. doi: 10.3389/fmed.2020.00237

170. Vázquez-Castellanos JF, Biclot A, Vrancken G, Huys GR, Raes J. Design of synthetic microbial consortia for gut microbiota modulation. Curr Opin Pharmacol. (2019) 49:52-59. doi: 10.1016/j.coph.2019.07.005

171. Schulenburg H, Félix MA. The natural biotic environment of Caenorhabditis elegans. Genetics. (2017) 206:55-86. doi: 10.1534/genetics.116.195511

172. Muller C, Mazel V, Dausset C, Busignies V, Bornes S, Nivoliez A, et al. Study of the Lactobacillus rhamnosus Lcr35 $(\mathrm{R}$ properties after compression and proposition of a model to predict tablet stability. Eur J Pharm Biopharm. (2014) 88:787-94. doi: 10.1016/j.ejpb.2014.07.014

173. Nivoliez A, Veisseire P, Alaterre E, Dausset C, Baptiste F, Camarès O, et al. Influence of manufacturing processes on cell surface properties of probiotic 
strain Lactobacillus rhamnosus Lcr35®. Appl Microbiol Biotechnol. (2015) 99:399-411. doi: 10.1007/s00253-014-6110-z

174. Hwang S-B, Choi J, Wei S, Park B-J, Chelliah R, Oh D-H. In vivo screening platform for shiga toxin-producing Escherichia coli (STEC) using Caenorhabditis elegans as a model. PLoS ONE. (2018) 13:e0193277. doi: 10.1371/journal.pone.0193277

175. Wan L, Lin J, Du H, Zhang Y, Bravo A, Soberón M, et al. Bacillus thuringiensis targets the host intestinal epithelial junctions for successful infection of Caenorhabditis elegans. Environ Microbiol. (2019) 21:108698. doi: $10.1111 / 1462-2920.14528$

176. Gerbaba TK, Gupta P, Rioux K, Hansen D, Buret AG. Giardia duodenalis induced alterations of commensal bacteria kill Caenorhabditis elegans : a new model to study microbial-microbial interactions in the gut. Am J Physiol Liver Physiol. (2015) 308:G550-61. doi: 10.1152/ajpgi.00335.2014

177. Cruz MR, Graham CE, Gagliano BC, Lorenz MC, Garsin DA. Enterococcus faecalis inhibits hyphal morphogenesis and virulence of Candida albicans. Infect Immun. (2013) 81:189-200. doi: 10.1128/IAI.00914-12

178. Scanlan LD, Lund SP, Coskun SH, Hanna SK, Johnson ME, Sims CM, et al. Counting Caenorhabditis elegans: protocol optimization and applications for population growth and toxicity studies in liquid medium. Sci Rep. (2018) 8:904. doi: 10.1038/s41598-018-19187-3

179. Josende ME, Nunes SM, Müller L, Ferreira-Cravo M, Monserrat JM, Ventura-Lima J. Circular estimate method (CEM) - a simple method to estimate Caenorhabditis elegans culture densities in liquid medium. Biol Proced Online. (2019) 21:1. doi: 10.1186/s12575-018-0089-2

180. Mondal S, Hegarty E, Martin C, Gökçe SK, Ghorashian N, Ben-Yakar A. Large-scale microfluidics providing high-resolution and high-throughput screening of Caenorhabditis elegans poly-glutamine aggregation model. Nat Commun. (2016) 7:13023. doi: 10.1038/ncomms13023

181. Cornwell AB, Llop JR, Salzman P, Thakar J, Samuelson AV. The replica set method: a high-throughput approach to quantitatively measure Caenorhabditis elegans lifespan. J Vis Exp. (2018) 136:57819. doi: $10.3791 / 57819$

182. Tharmalingam N, Rajmuthiah $\mathrm{R}$, Kim W, Fuchs BB, Jeyamani E, Kelso MJ, et al. Antibacterial properties of four novel hit compounds from a methicillin-resistant Staphylococcus aureusCaenorhabditis elegans high-throughput screen. Microb Drug Resist. (2018) 24:666-74. doi: 10.1089/mdr.2017.0250

183. Kim SM, Escorbar I, Lee K, Fuchs BB, Mylonakis E, Kim W. Anti-MRSA agent discovery using Caenorhabditis elegans-based high-throughput screening. J Microbiol. (2020) 58:431-44. doi: 10.1007/s12275-0200163-8

184. Zanni E, Laudenzi C, Schifano E, Palleschi C, Perozzi G, Uccelletti D, et al. Impact of a complex food microbiota on energy metabolism in the model organism Caenorhabditis elegans. Biomed Res Int. (2015) 2015:112. doi: $10.1155 / 2015 / 621709$

Conflict of Interest: AN had an institutional affiliation with the company which manufactures Lcr35 products. AN was employed by the company biose ${ }^{\circledR}$ Industrie.

The remaining authors declare that the research was conducted in the absence of any commercial or financial relationships that could be construed as a potential conflict of interest.

Copyright $\odot 2020$ Poupet, Chassard, Nivoliez and Bornes. This is an open-access article distributed under the terms of the Creative Commons Attribution License (CC $B Y)$. The use, distribution or reproduction in other forums is permitted, provided the original author(s) and the copyright owner(s) are credited and that the original publication in this journal is cited, in accordance with accepted academic practice. No use, distribution or reproduction is permitted which does not comply with these terms. 